\title{
1 Spreading of a mycobacterial cell surface lipid into host epithelial membranes promotes 2 infectivity
}

C.J. Cambier ${ }^{1}$, Steven M. Banik${ }^{1}$, Joseph A. Buonomo ${ }^{1}$, and Carolyn R. Bertozzi ${ }^{1,2, *}$

5

${ }^{1}$ Department of Chemistry, Stanford University, Stanford, CA, 94305, USA

\section{ABSTRACT}

Several virulence lipids populate the outer cell wall of pathogenic mycobacteria (Jackson, 2014). Phthiocerol dimycocerosate (PDIM), one of the most abundant outer membrane lipids

13 (Anderson, 1929), plays important roles in both defending against host antimicrobial programs

14 (Camacho et al., 2001; Cox et al., 1999; Murry et al., 2009) and in evading these programs

15 altogether (Cambier et al., 2014a; Rousseau et al., 2004). Immediately following infection,

16 mycobacteria rely on PDIM to evade toll-like receptor (TLR)-dependent recruitment of

17 bactericidal monocytes which can clear infection (Cambier et al., 2014b). To circumvent the

18 limitations in using genetics to understand virulence lipid function, we developed a chemical

19 approach to introduce a clickable, semi-synthetic PDIM onto the cell wall of Mycobacterium

20 marinum. Upon infection of zebrafish, we found that PDIM rapidly spreads into host epithelial

21 membranes, and that this spreading inhibits TLR activation. PDIM's ability to spread into

22 epithelial membranes correlated with its enhanced fluidity afforded by its methyl-branched

23 mycocerosic acids. Additionally, PDIM's affinity for cholesterol promoted its occupation of

24 epithelial membranes; treatment of zebrafish with statins, cholesterol synthesis inhibitors,

25 decreased spreading and provided protection from infection. This work establishes that

26 interactions between host and pathogen lipids influence mycobacterial infectivity and suggests

27 the use of statins as tuberculosis preventive therapy by inhibiting PDIM spread.

\section{INTRODUCTION}

30 Mycobacterium tuberculosis, the causative pathogen of the pulmonary disease

31 tuberculosis (TB), is estimated to have evolved within the confines of the human lung for 
32 millennia (Comas et al., 2013). A result of this co-evolution is a choreographed response of

33 innate and adaptive immune cells culminating in the formation of granulomas, specialized

34 structures that permit bacterial replication and ultimately promote transmission (Ramakrishnan,

35 2012). A key strategy used by mycobacteria throughout infection is to avoid and manipulate host

36 immune pathways so as to afford the pathogen safe harbor in otherwise bactericidal myeloid

37 cells (Cambier et al., 2014a; Urdahl, 2014).

To better understand these host-pathogen interactions, we have taken advantage of the optically transparent zebrafish larva, a natural host of the pathogen M. marinum (Ramakrishnan, 2020; Takaki et al., 2013). Infection of the hindbrain ventricle (HBV), an epithelium-lined cavity, allows for the visualization and characterization of the cellular immune response (Davis and Ramakrishnan, 2009), a response that is comparable to that seen in the mouse lung following infection with M. tuberculosis (Srivastava et al., 2014). In both models, mycobacteria are initially phagocytosed by tissue-resident macrophages and are eventually transferred to monocytes which go on to form granulomas (Cambier et al., 2017; Cohen et al., 2018).

In order to reach growth-permissive cells, mycobacteria must first evade prototypical anti-bacterial monocytes. In response to mucosal commensal pathogens, bactericidal monocytes are recruited downstream of TLR signaling (Medzhitov, 2007). Screening of M. marinum genetic mutants found that the cell surface lipid phthiocerol dimycocerosate (PDIM) is required to avoid this TLR-dependent immune response (Cambier et al., 2014b). In addition to evading immune detection, PDIM is reported to promote pathogenesis in other ways, such as being required for the relative impermeability of the mycobacterial cell wall (Camacho et al., 2001) and promoting escape from phagolysosomes (Augenstreich et al., 2017; Barczak et al., 2017; Lerner et al., 2017; Quigley et al., 2017). However, the molecular details underlying PDIM's myriad pathogenic functions remain unknown.

To accomplish mechanistic studies of virulence lipids, we and others developed

58 (Siegrist et al., 2015). The unnatural metabolite contains a bioorthogonal functional group that facilitates visualization of macromolecules in living bacteria (Sletten and Bertozzi, 2009). An

60 example is the labeling of trehalose containing lipids with azide-functionalized trehalose (Swarts 61 et al., 2012). Trehalose labeling is so robust that it has since been elaborated on with various functional probes (Kamariza et al., 2018; Rodriguez-Rivera et al., 2017). 
Here we have developed comparable chemical tools to monitor PDIM's distribution during infection, allowing us to better understand PDIM's mechanism of action. By visualizing PDIM during in vivo infection, we found that the first step in PDIM mediated pathogenesis is to spread into epithelial cells in order to inhibit TLR signaling. Structure function analysis revealed that PDIM's inherent fluidity, afforded by its methyl-branched fatty acids, promoted occupation of this host lipid niche. PDIM spreading was also dependent on the lipid content of host membranes. Administration of the cholesterol lowering drug, atorvastatin (Lipitor), led to a decrease in PDIM spreading, and subsequent resistance to mycobacterial infection. Our findings provide a mechanistic explanation for the association of statin use with a decrease in TB incidence (Lai et al., 2016a) and support their use as a TB preventative therapy.

\section{RESULTS}

\section{Controlling Mycomembrane Composition by Chemical Extraction and Reconstitution}

Due to the conserved synthesis of lipid intermediates, PDIM lacks unique biosynthetic precursors to facilitate metabolic labeling (Onwueme et al., 2005). However, PDIM is removed following petroleum ether extraction (Moliva et al., 2019), a technique previously used to perform loss of function studies of outer mycomembrane lipids (Silva et al., 1985), as lipids can be removed and added back with petroleum ether (Indrigo, 2003). Using this approach, we

81 hypothesized that we could chemically install a biorthogonal handle onto extracted PDIM and use this modified lipid to elucidate the fundamental mechanisms underlying PDIM's contribution to virulence. Similar to reports on M. tuberculosis and M. bovis, we validated that petroleum

84 ether extraction did not affect the growth rate of $M$. marinum in culture (Supplemental Figure

85 1A) and extracted lipids could be mixed with bacteria in petroleum ether followed by drying to

86 reconstitute these lipids into the mycomembrane (Figure 1A and Supplemental Figure 1B).

87 Similar to reports in macrophages (Indrigo, 2003), following infection of zebrafish (Figure 1B)

88 delipidated bacteria were attenuated for growth and this phenotype was rescued upon

89 reconstitution (Figure $1 \mathrm{C}$ and $\mathrm{D}$ ).

\section{Pre-infection PDIM Reservoirs are Required for Virulence}

92 M. marinum mutants in PDIM synthesis ( $\Delta$ mas) and localization to the mycomembrane

93 ( $\Delta m m p L 7)$ trigger TLR-dependent immune recognition following infection (Cambier et al., 
A

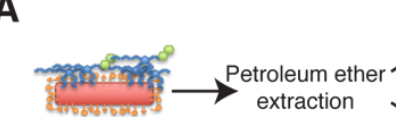
Lyophilized $M$. marinum control group
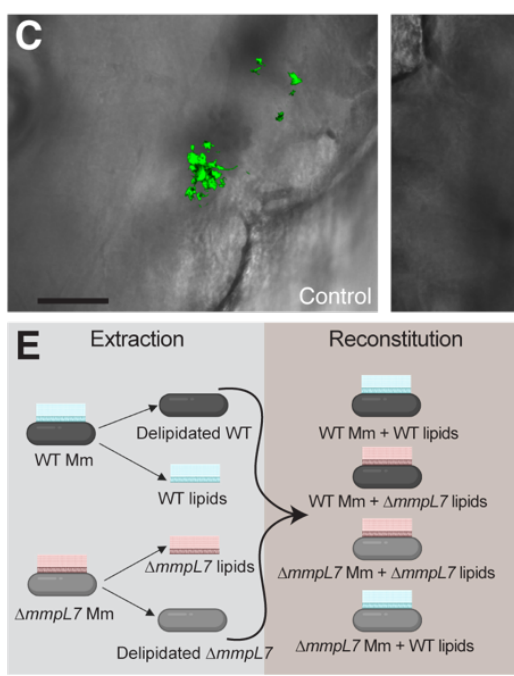

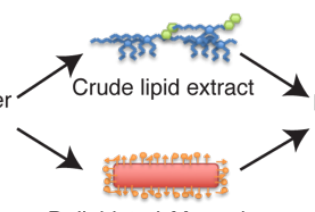

Delipidated M. marinum
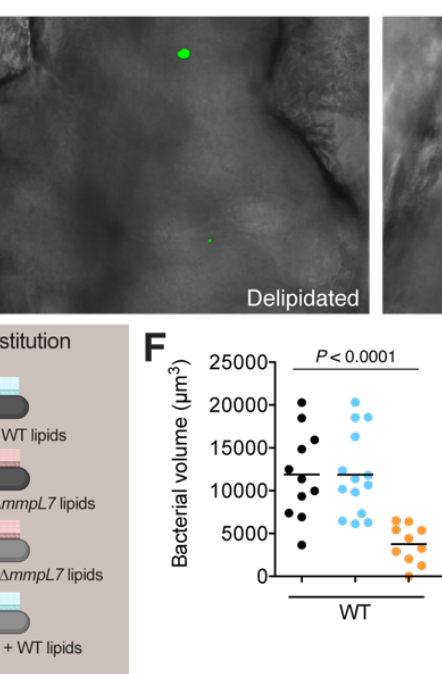

B

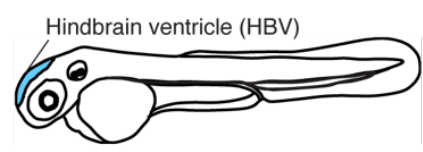

Reconstituted M. marinum
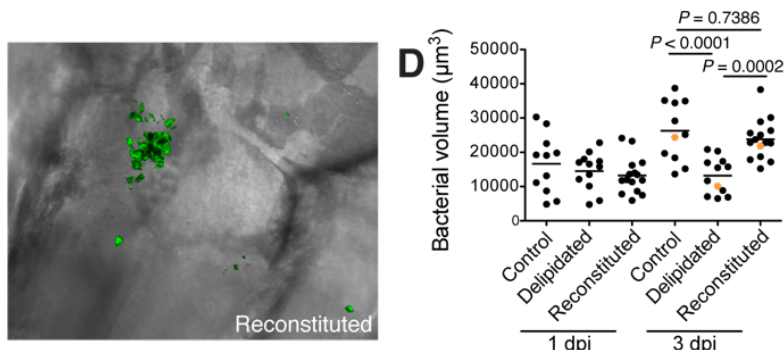

G

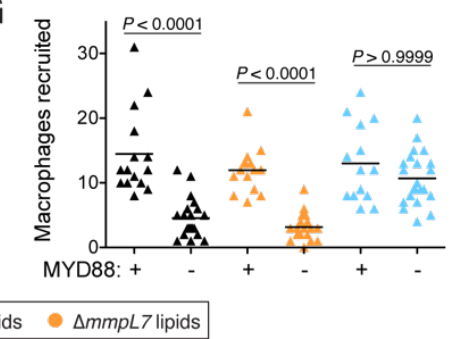

Figure 1. Chemical extraction and reconstitution reveals that pre-infection PDIM reservoirs are required for virulence. (A) Model of chemical extraction and reconstitution. (B) Model of zebrafish larva showing the hindbrain ventricle (HBV) injection site. (C) Representative images of the experiment in $\mathbf{D}$ (orange dots), scale bar $=50 \mu \mathrm{m}$. (D) Mean bacterial volume after HBV infection of wildtype fish with $\sim 100$ control, delipidated, or reconstituted M. marinum. (E) Model of lipid swap experiment. (F) Mean bacterial volume after HBV infection of wildtype fish with $\sim 100$ WT or $\triangle m m p L 7 M$. marinum treated as follows: non-extracted control (black), extracted and reconstituted with WT lipids (blue), or extracted and reconstituted with $\Delta m m p L 7$ lipids (orange). (G) Mean macrophage recruitment at $3 \mathrm{hpi}$ of the HBV with $\sim 100 \triangle m m p L 7 \mathrm{M}$. marinum as treated in $\mathbf{F}$. (D), (F), and (G) representative of at least three separate experiments. Ordinary one-way ANOVA with (D) Sidak's multiple comparisons test for the comparison's shown and (F) Tukey's multiple comparisons test with selected adjusted $P$ values shown. (G) Kruskal-Wallis ANOVA for unequal variances with Dunn's multiple comparisons test with selected adjusted $P$ values shown.

2014b). TLR signaling leads to the recruitment of activated monocytes that can clear bacteria in an inducible nitric oxide synthase-dependent fashion. PDIM-sufficient wildtype bacteria are not

97 detected by TLRs and instead recruit a comparable number of permissive monocytes

98 downstream of the chemokine CCL2 (Cambier et al., 2014b). However, since $\Delta m a s$ and

$99 \Delta m m p L 7$ lack proteins required for PDIM's synthesis or export, the associated phenotypes could

100 be attributed to the missing proteins rather than to a lack of PDIM. To directly test if the

101 presence of PDIM on the bacterial surface is responsible for evasion of TLR-mediated immunity,

102 we performed a lipid-swap experiment. Wildtype and $\triangle m m p L 7$ M. marinum were either

103 untreated (control) or extracted and reconstituted with their native lipids or the lipids from the

104 other strain (Figure 1E). Petroleum ether extraction of wildtype bacteria completely removed

105 both dimycocerosic acid (DIM) containing lipids, PDIM and its metabolic precursor 
106 phthiodiolone dimycocerosate (PNDIM, Supplemental Figure 1C) both of which were absent in

$107 \Delta m m p L 7$ extracts (Supplemental Figure 1D). Following infection, wildtype control and wildtype

108 bacteria reconstituted with wildtype lipids grew normally whereas wildtype bacteria

109 reconstituted with $\triangle m m p L 7$ lipids were attenuated for growth (Figure 1F). Conversely, $\Delta m m p L 7$

110 bacteria were attenuated for growth, as expected, unless they were reconstituted with wildtype

111 lipids, in which case they grew at wildtype bacterial rates (Figure 1F). Using an antisense

112 morpholino to knockdown the TLR-adaptor MYD88 (Bates et al., 2007), we also found that the

113 dependence on TLRs to recruit monocytes to $\triangle m m p L 7$ bacteria was abolished with wildtype

114 lipids (Figure 1G). Taken together these experiments highlight the strengths of this chemical

115 approach. Not only does it recapitulate known phenotypes of PDIM genetic mutants, but it

116 directly links the mutant phenotypes to the absence of PDIM on the mycomembrane.

117 Furthermore, our data suggest that the PDIM present on the surface of the bacterium from the

118 onset of infection is required and sufficient to avoid TLRs, as mutants unable to replenish PDIM

119 on their surfaces become virulent when they are coated with wildtype lipids prior to infection.

\section{Synthesis of a Clickable, Biologically Active PDIM}

122 Given the pathogenic importance of the pre-infection mycomembrane lipid content, we

123 hypothesized that labeling this pool of PDIM would allow us to observe characteristics

124 underlying its virulence mechanisms. Both PDIM and its biosynthetic precursor PNDIM are

125 present in the outer mycomembrane. The only difference between these lipids is their diol

126 backbones; PDIM has a methyl ether, while PNDIM has a ketone (Siméone et al., 2007). Either

127 lipid alone can promote infection in mice (Siméone et al., 2007), suggesting chemical flexibility

128 at this site with regards to virulence. Therefore, we converted the methyl ether of PDIM to an

129 alkyl halide with trimethylsilyl iodide (Jung and Lyster, 1977). Subsequent addition of sodium

130 azide provided azido-DIM (Figure 2A). Reconstitution of delipidated bacteria with lipids

131 containing azido-DIM, followed by a copper-free click reaction with the cyclooctyne fluorophore

132 DIBO-488 (Figure 2B) resulted in a 100-fold increase in fluorescence (Figure 2C). Confocal

133 microscopy revealed the fluorescent signal to be membrane associated (Figure 2D, E),

134 suggesting azido-DIM incorporated into the mycomembrane. Importantly, we found that adding

135 back native DIMs or azido-DIM to DIM-depleted lipids prior to reconstitution (Supplemental

136 Figure 1E) followed by DIBO-488 labeling rescued DIM-depleted bacteria's growth attenuation 


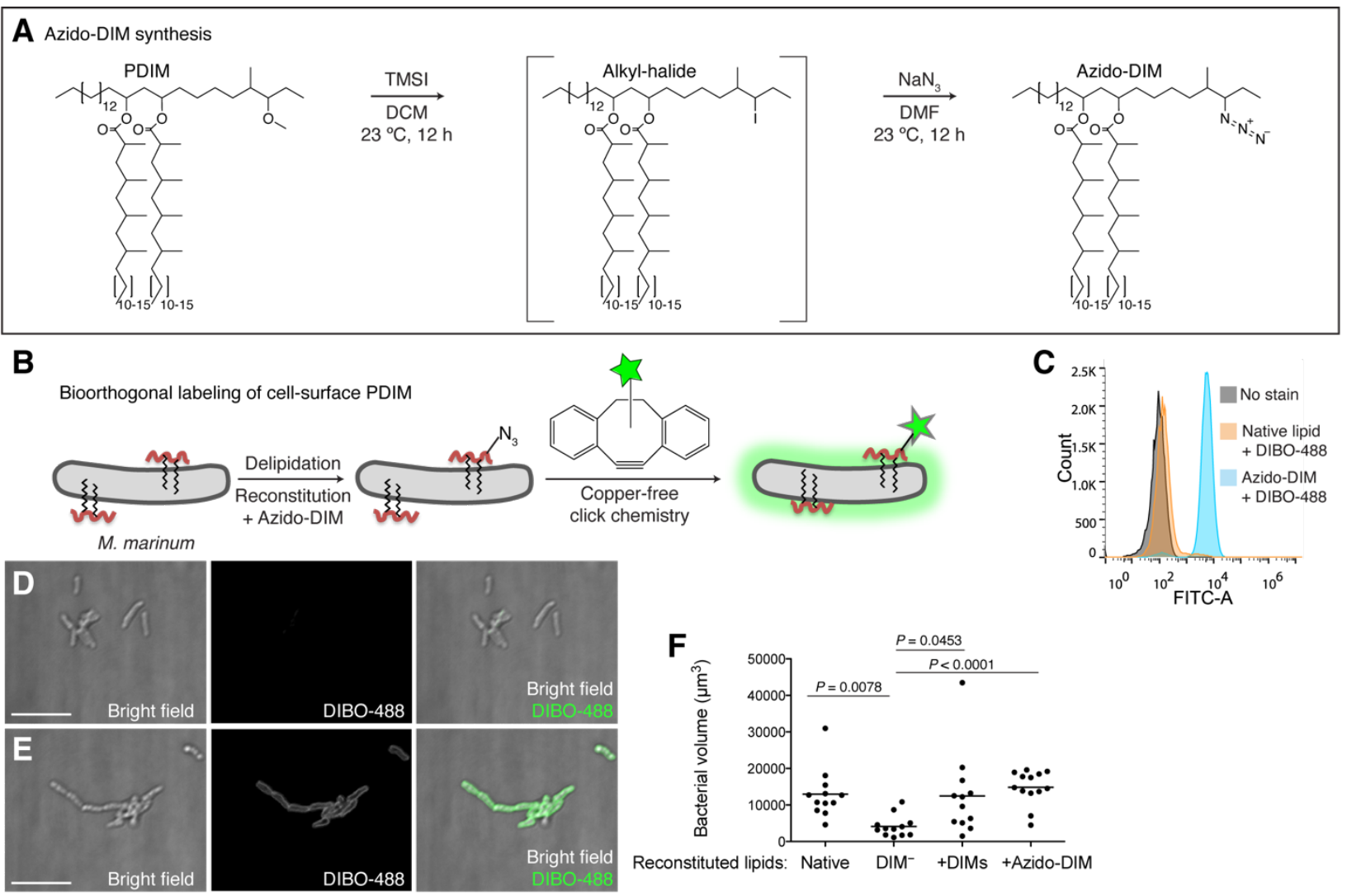

Figure 2. Synthesis and application of a chemically tractable, biologically active PDIM variant, azido-DIM. (A) Synthesis of azido-DIM. (B) Model of delipidation and reconstitution of bacteria with or without azido-DIM followed by treatment with an azide-reactive cyclooctyne, DIBO-488. (C) Flow cytometry analysis of control or azido-DIM reconstituted bacteria treated or untreated with DIBO-488. Image of (D) control or (E) azido-DIM reconstituted bacteria treated with DIBO-488, scale bar $=8 \mu \mathrm{m}$. $(\mathrm{F})$ Mean bacterial volume 3 days following HBV infection of wildtype fish with $\sim 100$ delipidated $M$. marinum reconstituted with Native, DIM depleted (DIM-), DIM- plus native DIMs (+DIMs), or DIM- plus azido-DIM (+Azido-DIM) lipids. Kruskal-Wallis ANOVA for unequal variances with Dunn's multiple comparisons test with selected adjusted $P$ values shown. (C)-(F) representative of three separate experiments.

138 (Figure 2F). Thus, with this approach we can generate bacteria with chemically functionalized

139 PDIM that retain their pathogenicity.

\section{PDIM Spreads into Host Cell Membranes In Vivo}

To visualize PDIM's distribution, we infected zebrafish with blue-fluorescent $M$.

143 marinum that were reconstituted with azido-DIM followed by labeling with DIBO-488 (DIM-

144 488). Immediately following phagocytosis, DIM-488 appeared to spread away from bacteria into

145 host membranes (Supplemental Figure 2A). Real-time imaging revealed that the spreading was

146 dynamic in nature, with DIM-488 deposits moving relative to host cells (Supplemental Movie 1).

147 To better visualize spreading of PDIM, we used the transgenic zebrafish line

$148 \mathrm{Tg}$ (mfap4:tdTomato) whose macrophages express the fluorescent protein tdTomato (Walton et 
al., 2015). As early as 3 hours post-infection (hpi), DIM-488 had spread into infected

150 macrophage membranes, at both phagosome (Figure 3A, arrows) and more distal membrane sites

151 (Figure 3A, arrow heads). Spreading increased across macrophage membranes by 3 days post-

152 infection (dpi) (Figure 3B). Similar spreading was seen when azido-DIM was conjugated to

153 DIBO-647 (Supplemental Figure 2B, C), suggesting that the lipid, and not the fluorescent probe,

154 was responsible for this phenotype. To quantify the extent of PDIM spreading, we imaged the

155 entire HBV infection site and calculated the proportion of fluorophore labelled azido-DIM that

156 no longer localized with bacteria (Supplemental Figure 2D). Using this number as a proxy for

157 lipid spread, we saw an increase in spreading as infection progressed (Figure 3C). Spreading also

158 occurred following infection of THP-1 macrophages in culture (Supplemental Figure 2E).

These results were consistent with a recent report using cultured macrophages showing

that M. tuberculosis PDIM occupies their cell membranes (Augenstreich et al., 2019).

161 Nevertheless, we wanted to determine whether spreading was a true attribute of our labeled

162 PDIM or if it was an artifactual property due to our reconstitution method. To address this, we

163 used an established pan-glycolipid labeling method previously used to track the spread of

164 mycobacterial glycolipids into macrophage membranes (Beatty et al., 2000). Control and

165 reconstituted $M$. marinum were treated with periodate and then reacted with a fluorescent

166 hydroxylamine prior to infection (Beatty et al., 2000). We found that spreading of the total pool

167 of fluorophore-labeled glycolipids was equal between control and reconstituted bacteria

168 (Supplemental Figure 3A and B). Thus, reconstitution does not appreciably influence the

169 spreading dynamics of mycomembrane lipids. These data demonstrate that the introduction of a

170 chemically functionalized PDIM into the mycomembrane provides physiologically relevant

171 information regarding PDIM's host distribution during in vivo infection.

172 We next wanted to understand how PDIM spreading might be promoting virulence.

173 While it is appreciated that mycobacterial lipids spread throughout macrophage membranes

174 (Beatty et al., 2000), the inability to track specific lipids in an in vivo setting has hampered

175 studies on the pathophysiological relevance of these observations. PDIM has been suggested to

176 interact with the protein substrates of the type VII secretion system ESX-1, including EsxA

177 (Barczak et al., 2017). PDIM and EsxA are both required for cytosolic escape from

178 phagolysosomes (Osman et al., 2020; Quigley et al., 2017; van der Wel et al., 2007), where

179 PDIM is suggested to enhance the pore forming activity of EsxA through its ability to infiltrate 

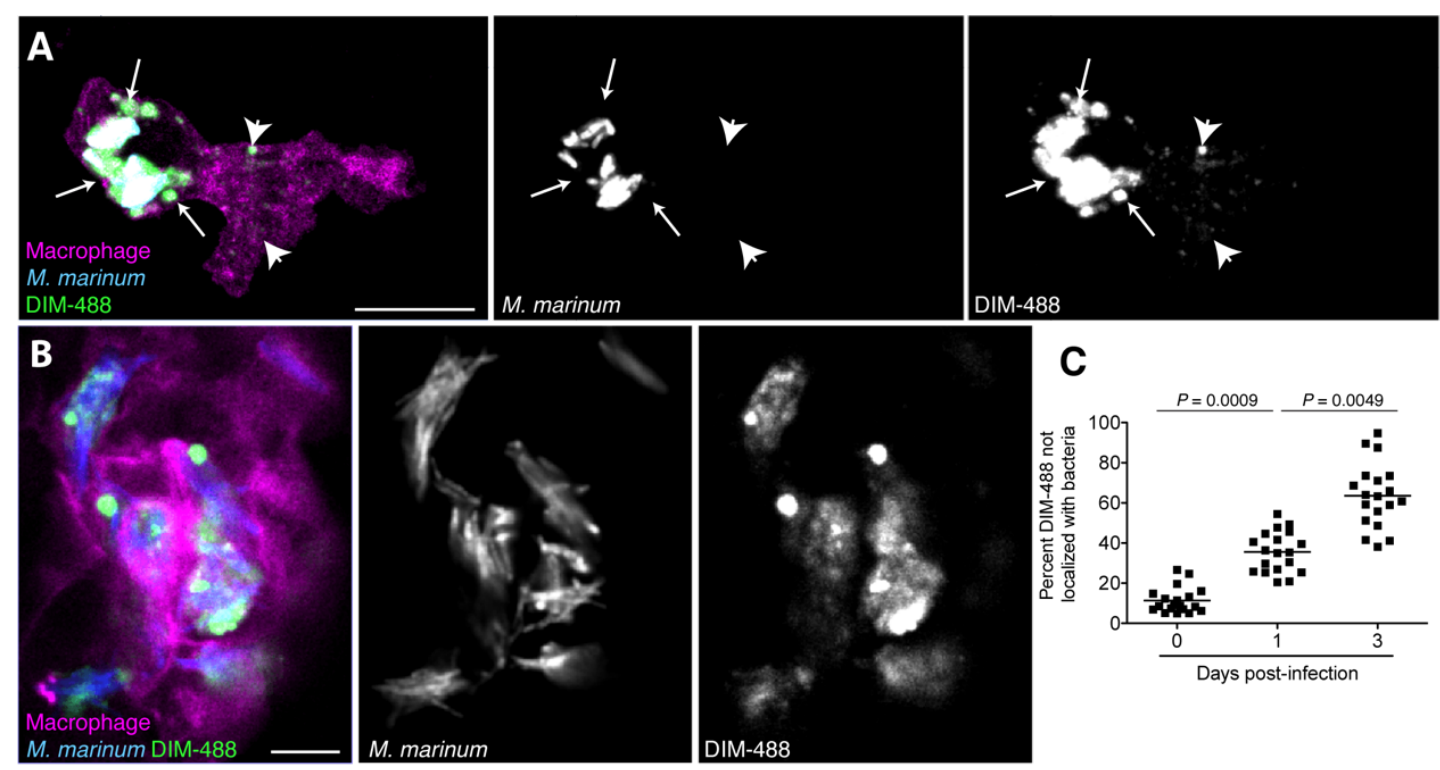

C
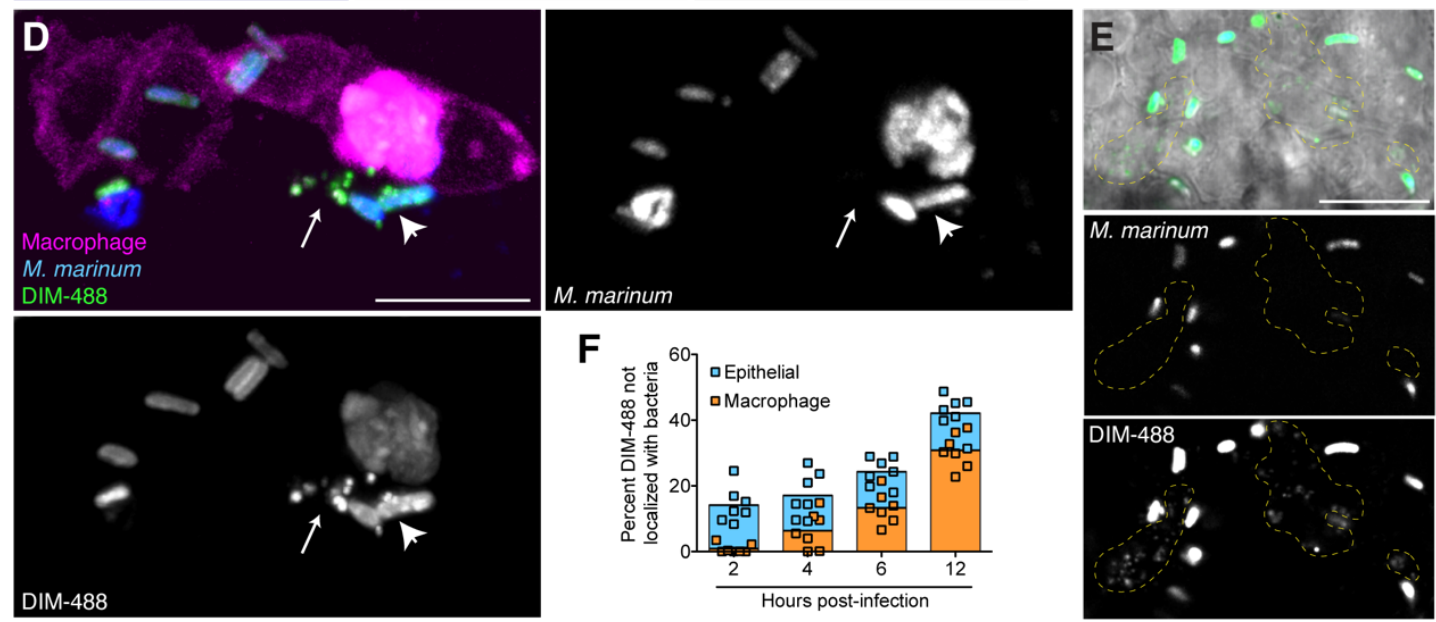

Figure 3. PDIM spreads into host cell membranes. Images of $M$. marinum expressing a cytosolic blue fluorescent protein reconstituted with DIBO-488 labeled azido-DIM (DIM-488) at (A) 3 hpi and (B) 3 dpi of $\sim 100$ M. marinum in the HBV of transgenic fish whose macrophages express a fluorescent protein. Scale bar $=10$ $\mu \mathrm{m}$. Arrows, DIM-488 spread in vicinity of phagosome, arrowheads, DIM-488 spread throughout macrophage. (C) Mean percent DIM-488 not localized with bacteria following HBV infection of wildtype fish with $\sim 100$ M. marinum. Kruskal-Wallis ANOVA for unequal variances with Dunn's multiple comparisons test with selected adjusted $P$ values shown. Representative of at least three separate experiments. (D) Image highlighting DIM-488 spread from bacteria (arrowhead) to epithelial cells (arrows) at $3 \mathrm{hpi}$ of $\sim 100 \mathrm{M}$. marinum in the HBV, colors correspond to features defined in A, scale bar $=10 \mu \mathrm{m}$. (E) Image highlighting DIM-488 spread onto epithelial surfaces (yellow-dashed outline) at $2 \mathrm{hpi}$ of $\sim 100 \mathrm{M}$. marinum in the HBV, scale bar = $10 \mu \mathrm{m}$. (F) Mean percent DIM-488 in macrophage or epithelial cells not localized with bacteria following HBV infection with $\sim 100$ M. marinum. Representative of two separate experiments.

181 macrophage membranes (Augenstreich et al., 2017). Thus, we hypothesized that PDIM

182 localization would be dependent on EsxA secretion. Region of difference-1 M. marinum mutants

183 ( $\triangle \mathrm{RD} 1)$ which lack EsxA (Volkman et al., 2010), were reconstituted with DIM-488 prior to

184 zebrafish infection. There was no difference in DIM-488 spreading kinetics between wildtype

185 and $\triangle$ RD1 M. marinum (Supplemental Figure 3C), suggesting that EsxA does not influence 
186 PDIM spreading. Besides playing a role in cytosolic escape, PDIM spreading into macrophage

187 membranes has also been shown to promote phagocytosis of extracellular bacteria (Astarie-

188 Dequeker et al., 2009; Augenstreich et al., 2019). To test this in vivo, we measured the rate of

189 phagocytosis of wildtype or $\triangle m m p L 7$ M. marinum following HBV infection by measuring the number of discrete bacterial objects over time. As bacteria are phagocytosed, individual bacteria can no longer be discerned by confocal microscopy and the number of discrete objects decreases.

192 There was no measurable difference in the rate of phagocytosis of wildtype or $\triangle m m p L 7$ bacteria

193 (Supplemental Figure 3D).

194 Given the discrepancy regarding PDIM's role in promoting phagocytosis between the 195 cultured macrophage and zebrafish models, we wondered if the activation state of responding 196 monocyte/macrophage populations in zebrafish larvae was influencing their phagocytic 197 capacities. We know that PDIM-deficient bacteria recruit antimicrobial monocytes downstream 198 of TLR signaling, whereas wildtype bacteria recruit permissive monocytes downstream of 199 CCL2/CCR2 signaling (Cambier et al., 2014b). We also know that wildtype bacteria depend on 200 resident macrophages to produce CCL2 in order to recruit CCR2-expressing monocytes, whereas 201 PDIM-deficient bacteria recruit monocytes independent of resident macrophages (Cambier et al., 202 2017). Therefore, we wondered if PDIM plays a critical role in evading TLR detection in non203 macrophage cell populations prior to any of its documented roles in directly modulating 204 macrophage biology. Upon closer examination, we observed DIM-488 deposits on zebrafish 205 epithelium at 24 hpi (Supplemental Figure 3E, arrows). Imaging at 3 hpi we captured 206 extracellular bacteria having spread DIM-488 in the vicinity of an infected macrophage (Figure 207 3D). This ability to spread into epithelial membranes was confirmed in human A549 epithelial 208 cells in vitro (Supplemental Figure 3F). To address the timing of PDIM spread into epithelial and 209 macrophage membranes we imaged infected zebrafish at 2 hpi, prior to macrophage

210 phagocytosis, and at 4, 6, and 12 hpi by which time the majority of bacteria are phagocytosed.

211 Preceding any appreciable spreading onto macrophages, DIM-488 had already spread onto

212 epithelial cells by 2 hpi (Figure 3E yellow outlines and 3F). These data suggest that

213 mycobacteria spread PDIM onto epithelial cells prior to interactions with macrophages. To

214 confirm this observation, we depleted macrophages from zebrafish larva using clodronate-loaded 215 liposomes (Bernut et al., 2014). DIM-488 spreading still occurred in the absence of macrophages 
216 (Supplemental Figure 3G). These data demonstrate that PDIM spreads onto epithelial cells

217 independent of and prior to macrophage phagocytosis.

\section{PDIM's Fluidity Promotes Spread into Epithelial Cell Membranes}

We sought to understand PDIM's properties that facilitated its ability to spread into host membranes. It is well established that increased membrane fluidity promotes membrane mixing

222 (Howell et al., 1972), leading us to ask if PDIM occupied membrane domains of high fluidity.

223 Previous studies from our lab found that the mycomembrane of Mycobacterium smegmatis is

224 relatively immobile by using fluorescence recovery after photobleaching (FRAP) of

225 metabolically labeled trehalose monomycolate (TMM) (Rodriguez-Rivera et al., 2017). We

226 confirmed this for M. marinum TMM. Using the metabolic label 6-azido-trehalose (Swarts et al.,

227 2012) followed by reaction with DIBO-488 to track TMM (TMM-488), we found very little

228 recovery following photobleaching of TMM-488, with only around $40 \%$ of the labeled lipids

229 being mobile (Figure 4A-C, and Supplemental Figure 4A). When we assessed PDIM, we found

230 DIM-488 recovery to be very efficient, with a half-life of 3 seconds and around $95 \%$ of the

231 signal being mobile (Figure 4A-C, and Supplemental Figure 4B). Thus, PDIM-containing

232 mycomembrane domains have a uniquely high fluidity.

233 If high membrane fluidity facilitates membrane mixing, then TMM should not be able to

234 spread into host cells as efficiently as PDIM does. Indeed, we found that TMM-488 failed to

235 spread onto epithelial cells at 2 hpi. Only when phagocytosed within macrophages at 24 hpi was

236 TMM spreading detected (Figure 4D and Supplemental Figure 4C). Even in the absence of

237 macrophages, where bacteria have a prolonged contact time with epithelial cells, TMM-488

238 spreading was negligible (Figure 4E). Thus, mycomembrane fluidity appears to correlate with

239 the ability to spread into host epithelial membranes.

240 To determine if there is a causal relationship between fluidity and spreading, we used

241 FRAP to identify conditions that decreased PDIM's recovery after photobleaching. Neither heat-

242 killing nor mild chemical fixation (4\% paraformaldehyde (PFA)) significantly reduced DIM-

243 488's recovery (Figure 4F, G and Supplemental Figure 5). However, fixation with 4\% PFA + 1\%

244 glutaraldehyde (GA), a more effective fixative for membrane-associated proteins (Huebinger et

245 al., 2018), resulted in an almost 80\% reduction in the mobile fraction of DIM-488 (Figure 4F, G

246 and Supplemental Figure 5). PFA+GA treatment decreased DIM-488 spread onto epithelial cells 
A
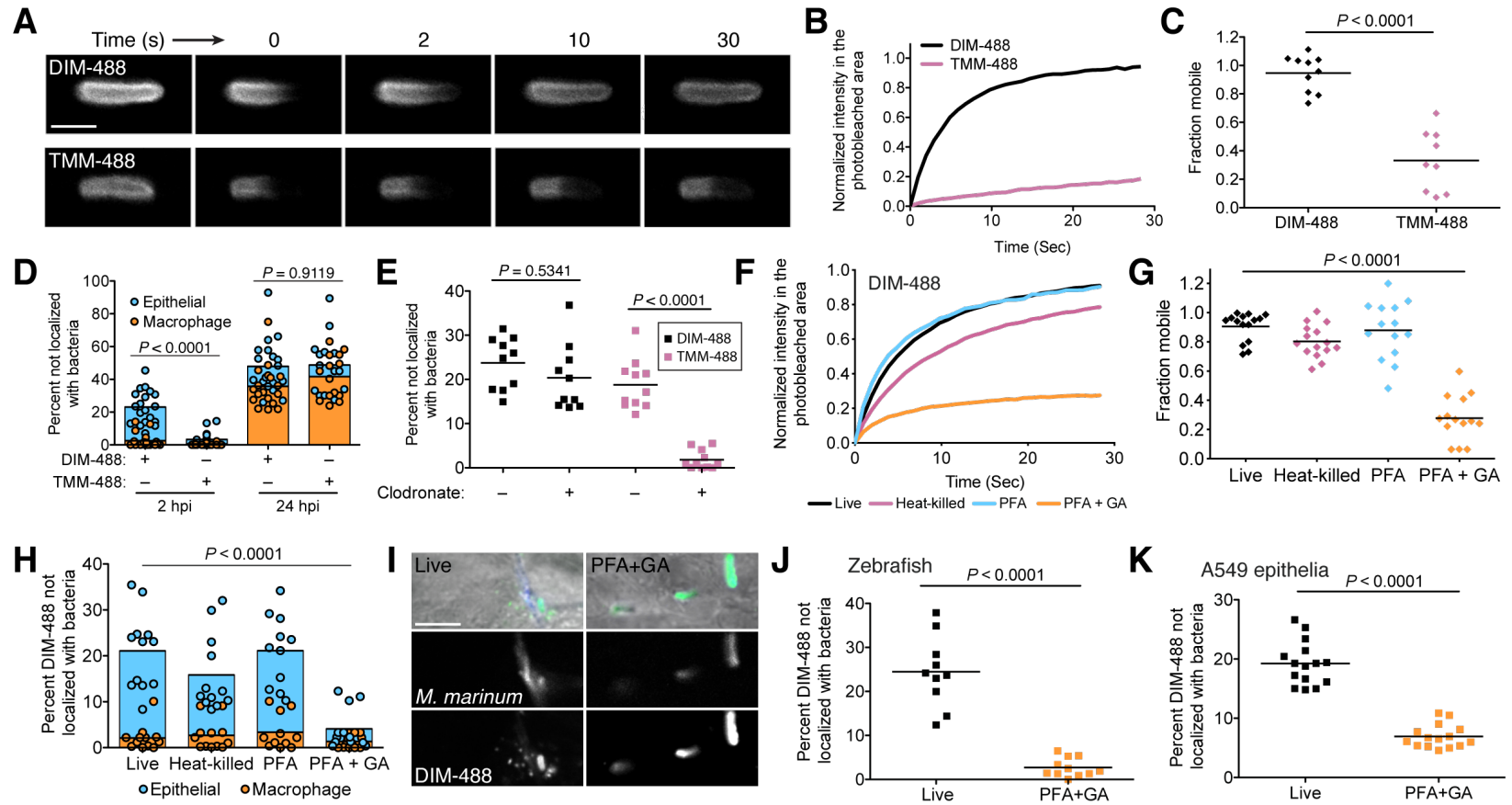

Figure 4. PDIM's mobility promotes spread into epithelial cells. (A) Representative FRAP images of DIM-488 and TMM-488 labeled $M$. marinum, scale bar $=2 \mu \mathrm{m}$. (B) Fluorescent recovery curves after photobleaching of DIM-488 or TMM-488 labeled M. marinum, lines represent the average signal from $n=10$ cells. (C) Mean fraction mobile following fitting of FRAP curves to data generated in B. (D) Mean percent DIM-488 or TMM-488 in macrophage or epithelial cells not localized with bacteria following HBV infection with $100 \mathrm{M}$. marinum, two-tailed Mann whitney test. (E) Mean percent DIM-488 or TMM-488 not localized with bacteria $24 \mathrm{~h}$ following HBV infection of lipo-PBS or lipo-clodronate treated fish with $\sim 100 \mathrm{M}$. marinum. (F) Fluorescent recovery curves after photobleaching of live, heat-killed, $4 \%$ paraformaldehyde (PFA) fixed, or $4 \%$ paraformaldehyde plus $1 \%$ glutaraldehyde (PFA+GA) fixed DIM-488 labeled $M$. marinum, lines represent the average signal from $n=14-15$ cells. (G) Mean fraction mobile following fitting of FRAP curves to data generated in F. (H) Mean percent DIM-488 in macrophage or epithelial cells not localized with bacteria $2 \mathrm{~h}$ following HBV infection with $\sim 100$ M. marinum treated as in F. (I) Images of live or PFA+GA treated DIM-488 labeled $M$. marinum at $2 \mathrm{hpi}$ of the HBV with $\sim 100$ bacteria, scale bar $=5 \mu \mathrm{m}$. Mean percent DIM-488 not localized with bacteria $24 \mathrm{~h}$ following $(\mathbf{J})$ infection of lipo-clodronate treated fish or $(\mathbf{K})$ A549 epithelial cells with live or PFA+GA fixed DIM-488 labeled M. marinum. (C), (J), and (K) two-tailed, unpaired t test. (E), (G), and $(\mathbf{H})$ ordinary one-way ANOVA with Tukey's multiple comparisons test with selected adjusted $P$ values shown. $(\mathbf{B})-(\mathbf{H})$ and $(\mathbf{J})-(\mathbf{K})$ representative of three separate experiments.

248 at 2 hpi (Figure 4H and 4I). Likewise, fixed DIM-488 did not spread into epithelial membranes

249 following a $24 \mathrm{~h}$ infection of macrophage-depleted zebrafish (Figure 4J). Nor did it spread onto

250 A549 epithelial cells after $24 \mathrm{~h}$ (Figure 4K). Together these results suggest that PDIM's fluidity

251 promotes spreading into epithelial membranes.

\section{PDIM's Methyl-Branched Mycocerosic Acids Promote Fluidity and Spreading}

To further test if PDIM's high membrane fluidity is responsible for its spreading, we 


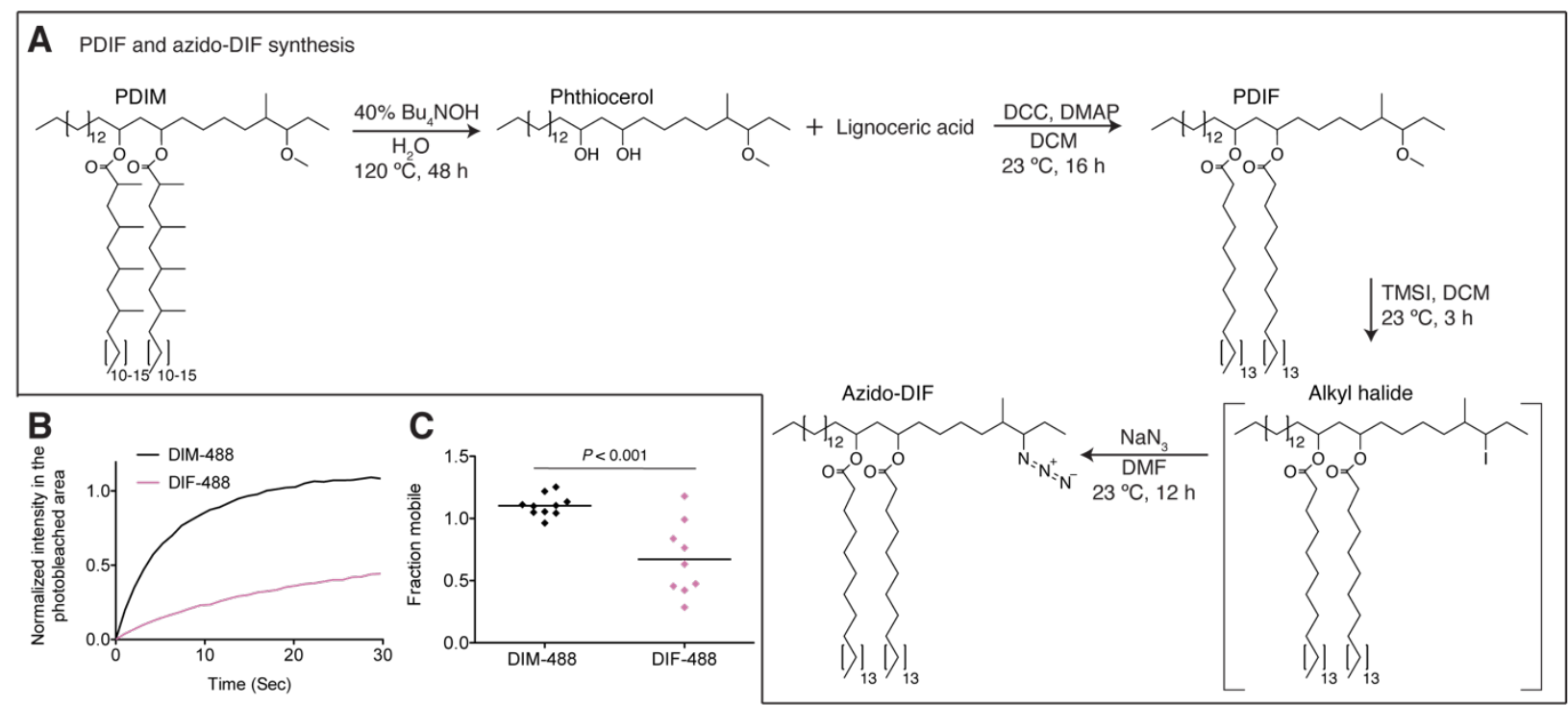

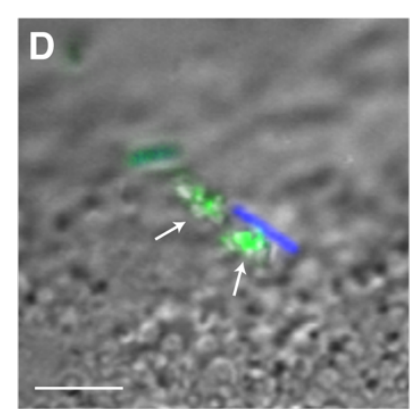

$\mathbf{F}$

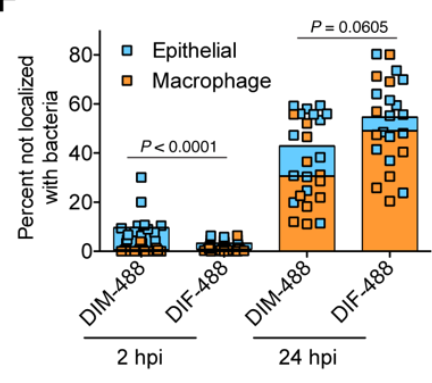

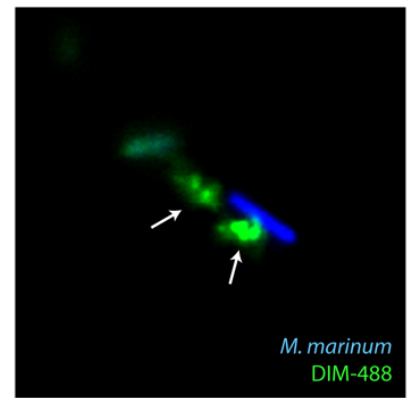
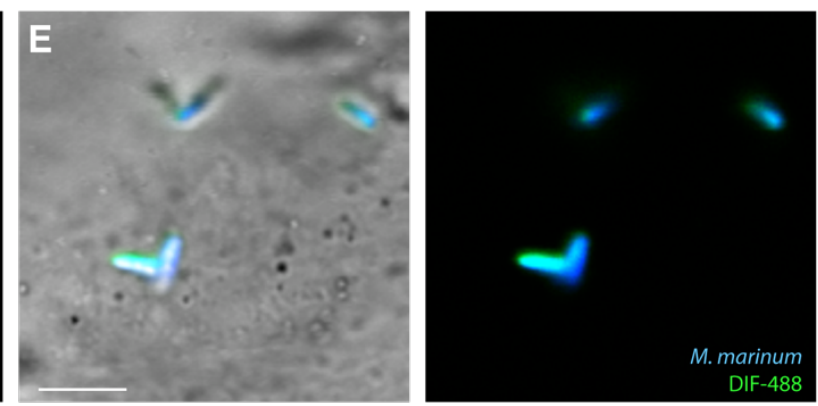

Figure 5. PDIM's methyl-branched mycocerosic acids are required for virulence.

(A) Phthiocerol di-fatty acid (PDIF) and azido-DIF synthesis. (B) Fluorescent recovery curves after photobleaching of DIM-488 or DIF-488 labeled M. marinum, lines represent the average signal from $n=9-10$ cells. (C) Fraction mobile following fitting of FRAP curves to data generated in $\mathbf{B}$. Two-tailed, unpaired $t$ test. Images of $M$. marinum expressing a blue fluorescent protein reconstituted with (D) DIM-488 or (E) DIF-488 at 2 hpi into the HBV of wildtype fish, arrows indicated spread signal, scale bar $=5 \mu \mathrm{m}$. (F) Mean percent DIM-488 or DIF-488 in macrophage or epithelial cells no longer localized with bacteria following HBV infection with $\sim 100$ M. marinum. Two-tailed Mann Whitney test for $2 \mathrm{hpi}$ and two-tailed, unpaired t test for $24 \mathrm{hpi}$. (B), (C), and (F) Representative of three separate experiments.

assemblies giving rise to more rigid bilayers, while unsaturated lipids do not pack as tightly and

produce more fluid bilayers. Methyl branches on otherwise saturated lipids have also been shown to increase membrane fluidity (Budin et al., 2018; Poger et al., 2014). Therefore, we

261 hypothesized that PDIM's methyl-branched mycocerosic acids determine its fluidity. To test this,

262 we hydrolyzed PDIM with tetrabutylammonium hydroxide to isolate phthiocerol. We then

263 esterified phthiocerol with the saturated fatty acid lignoceric acid that resulted in straight chain

264 lipids of comparable length to mycocerosic acid. This phthiocerol di-fatty acid (PDIF) was then

265 treated similarly to PDIM (Figure 2A) to yield the azide-labeled PDIF, azido-DIF (Figure 5A). 
266 FRAP studies confirmed that DIBO-488 labeled azido-DIF (DIF-488) was not as mobile as

267 DIM-488, with only $\sim 50 \%$ in the mobile fraction (Figure 5B, C and Supplemental Figure 6A-C).

268 Upon zebrafish infection, DIF-488 failed to spread onto epithelial cells at 2 hpi (Figure 5D-F).

269 However, similar to other mycobacterial lipids (Beatty et al., 2000) including TMM (Figure 4A),

270 DIF-488 was capable of spreading into macrophage membranes at later timepoints (Figure 5F

271 and Supplemental Figure 6D, E). Thus, PDIM's high fluidity mediated by its methyl-branched

272 lipid tails is the reason for its unique ability to spread into epithelial membranes.

\section{PDIM Spreading into Epithelial Membranes is Required to Evade TLRs}

Is PDIM spreading into epithelial membranes required to inhibit TLR signaling? We first

276 evaluated monocyte recruitment towards infecting mycobacteria to address this question.

277 Wildtype M. marinum must be alive in order to stimulate resident macrophages to express CCL2

278 to recruit permissive monocytes as heat-killed bacteria failed to do so (Cambier et al., 2017). In

279 contrast, PDIM-deficient M. marinum do not depend on resident macrophages to recruit

280 bactericidal monocytes and do so in a manner independent of bacterial viability (Cambier et al.,

281 2017). We now wondered if, in order for mycobacteria to gain access to resident macrophages,

282 PDIM must first spread into epithelial membranes to prevent recruitment of bactericidal

283 monocytes. We confirmed that heat-killed mycobacteria do not recruit monocytes (Figure 6A).

284 Likewise, PFA-treated bacteria which can also spread PDIM did not recruit monocytes (Figure

285 6A). However, monocyte recruitment towards PFA+GA treated bacteria, which do not spread

286 PDIM, phenocopied heat-killed $\triangle m m p L 7$ M. marinum; even though they are not viable, they

287 recruited monocytes to a similar extent as live bacteria (Figure 6A). Moreover, this monocyte

288 recruitment was now downstream of TLR signaling, as knockdown of MYD88 prevented

289 monocyte recruitment towards PFA+GA treated bacteria (Figure 6B). Taken together these data

290 demonstrate that PDIM spreading into epithelial membranes is required to prevent TLR-

291 dependent recruitment of monocytes.

292 TLR signaling has been shown to recruit microbicidal monocytes that kill infecting

293 bacteria (Cambier et al., 2014b). Not only are PDIM-deficient bacteria killed but co-infected

294 PDIM-expressing bacteria are as well (Cambier et al., 2014b). This latter finding allowed us to

295 directly examine the link between PDIM spreading and bacterial killing by resultant TLR-

296 signaled monocytes. We infected larvae with live red-fluorescent wildtype M. marinum along 
A
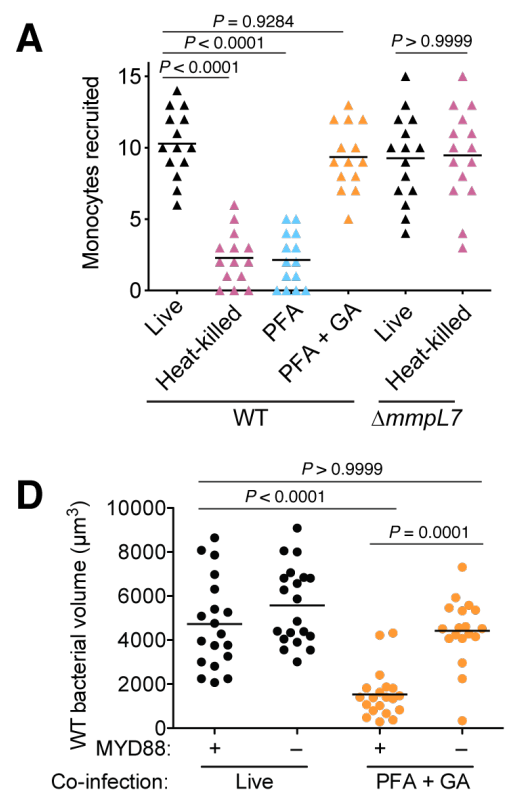

B
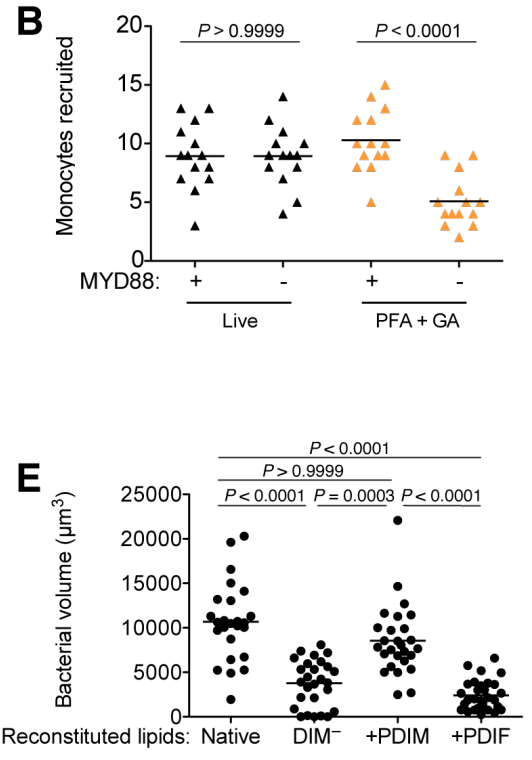

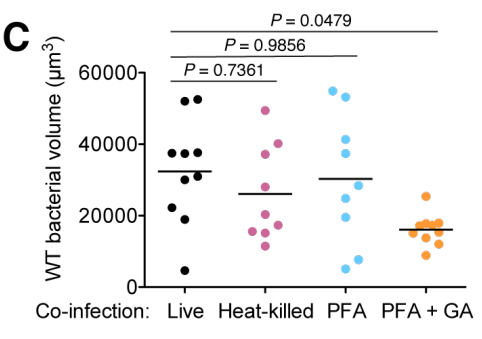

Reconstited lipis: Native DlM- tPDiM tPDiF

Figure 5. PDIM spreading into epithelial membranes is required to evade TLRs. (A) Mean monocyte recruitment at 3 hpi of the HBV with $\sim 100$ live, heat-killed, PFA treated, or PFA+GA treated wildtype (WT) or $\sim 100$ live or heat-killed $\triangle m m p L 7 M$. marinum. (B) Mean monocyte recruitment at $3 \mathrm{hpi}$ of the HBV of wildtype or MYD88-depleted fish with $\sim 100$ live or PFA+GA treated wildtype $M$. marinum. Mean volume of wildtype $M$. marinum following co-infection with (C) wildtype M. marinum treated as in A or (D) live or PFA+GA treated wildtype M. marinum in wildtype or MYD88-depleted fish. (E) Mean bacterial volume 3 days following HBV infection of wildtype fish with $\sim 100$ M. marinum reconstituted with Native, DIM-depleted (DIM-), DIM- plus PDIM (+PDIM), or DIM- plus PDIF (+PDIF) lipids. (A)-(C) ordinary one-way ANOVA with Tukey's multiple comparisons test with selected adjusted $P$ values shown. (D) and (E) Kruskal-Wallis ANOVA for unequal variances with Dunn's multiple comparisons test with selected adjusted $P$ values shown. (A)-(E) representative of three separate experiments.

298 with green-fluorescent wildtype $M$. marinum that were live (untreated), heat-killed, PFA treated, or PFA+GA treated and then determined the burdens of the red fluorescent wildtype M. marinum at 3 dpi. Only co-infection with PFA+GA treated bacteria caused attenuation of wildtype bacteria (Figure 6C). Moreover, this attenuation was dependent on MYD88 (Figure 6D). Lastly, we asked if PDIF, which is unable to spread into epithelial cells (Figure 4F), could rescue DIM-deficient bacterial growth similarly to PDIM (Figure 2F). Consistent with the requirement for PDIM to spread into epithelial cells to promote virulence, we found that reconstitution with PDIF does not rescue bacterial growth (Figure 6E). Together these findings implicate PDIM spreading into epithelial membranes in inhibiting TLR signaling and the resultant recruitment of microbicidal monocytes that can kill infecting mycobacteria. 


\section{Host Cholesterol Promotes PDIM Spread and Mycobacterial Infectivity}

312 We next asked if host lipids also influence PDIM spreading. Cholesterol has been

313 reported to modulate macrophage interactions with mycobacteria (Gatfield and Pieters, 2000).

314 However, three lines of evidence suggest a macrophage-independent relationship between

315 mycobacteria and cholesterol: 1) 36\% of the lipid extracted from Mycobacterium bovis harvested

316 from necrotic mouse lung (where macrophages are sparse) was found to be host cholesterol

317 (Kondo and Kanai, 1976); 2) mycobacterial-associated cholesterol was isolated as a mixture with

318 PDIM (Kondo and Kanai, 1976); 3) M. tuberculosis grown in culture can sequester cholesterol to

319 its outer mycomembrane, a process dependent on mycomembrane lipids (Brzostek et al., 2009).

320 To test if host cholesterol interacted with PDIM to facilitate its spreading, we first grew wildtype

321 and $\Delta m m p L 7$ M. marinum in the presence of alkyne-cholesterol (Supplemental Figure 7A) for 48

$322 \mathrm{~h}$, followed by treatment with azide-conjugated alexafluor-647. We found that only wildtype $M$.

323 marinum could sequester cholesterol to their mycomembrane (Figure 7A-C). We next tested

324 whether cholesterol contributes to spreading of PDIM into host membranes. We depleted

325 cholesterol from A549 epithelial cells with methyl $\beta$-cyclodextrin (MBCD) which resulted in an

326 eight-fold decrease in cholesterol (Supplemental Figure 7B). This was associated with decreased

327 DIM-488 spreading (Supplemental Figure 7C). Importantly, in MßCD treated cells we could

328 restore cholesterol to untreated levels with water-soluble cholesterol, and this restored DIM-488

329 spreading (Supplemental Figure 7B, C). To test if host cholesterol facilitates PDIM spreading in

330 vivo, we treated zebrafish with statins, drugs that inhibit HMG-CoA reductase, the rate-limiting

331 step of cholesterol biosynthesis. Specifically, we used atorvastatin which was shown to lower

332 cholesterol in zebrafish (Maerz et al., 2019). Following $24 \mathrm{~h}$ of treatment, atorvastatin decreased

333 cholesterol levels in the larvae by $25 \%$, and co-treatment with water-soluble cholesterol restored

334 cholesterol levels (Figure 7D). Atorvastatin treatment also decreased DIM-488 spreading onto

335 epithelial cells (Figure 7E and F), suggesting that PDIM's interaction with cholesterol promotes

336 spreading into epithelial membranes in vivo.

337 Hypercholesteremia has been shown to exacerbate mycobacterial infection in mice and

338 humans (Martens et al., 2008; Soh et al., 2016), and studies suggest the utility of statins both in

339 TB treatment and prevention. When used in mice, statins decreased the duration of TB therapy

340 by one month (Dutta et al., 2016), and studies of health care databases found that statin use is

341 associated with decreased incidence of TB (Kim et al., 2019; Lai et al., 2016b). Accordingly, we 
A

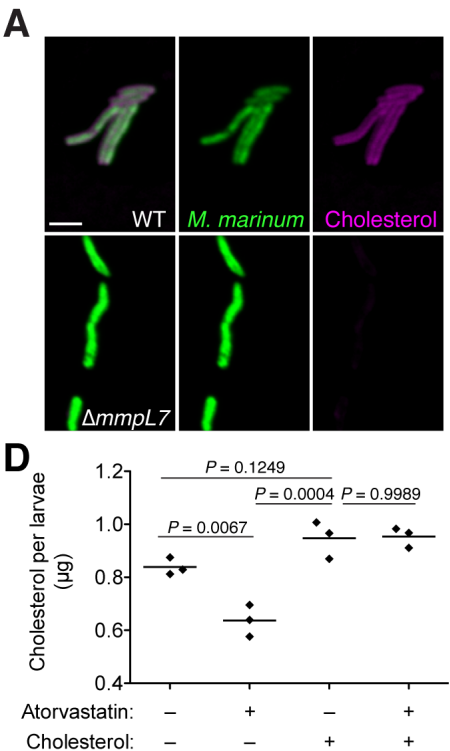

$\mathbf{F}$

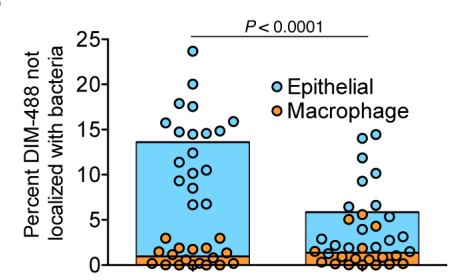

Atorvastatin:
B
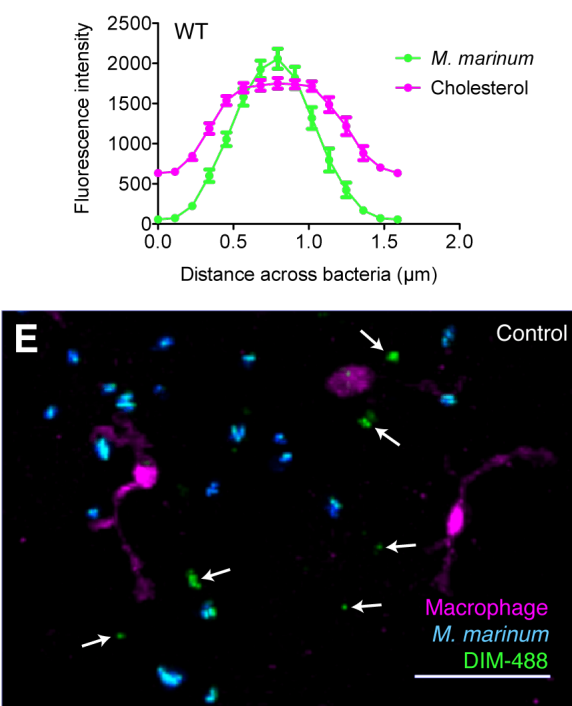

G

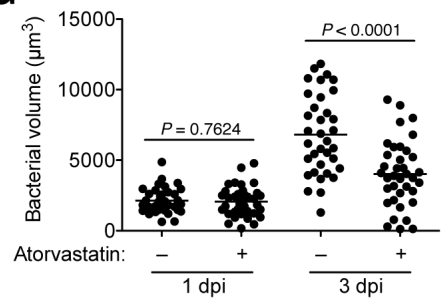

C
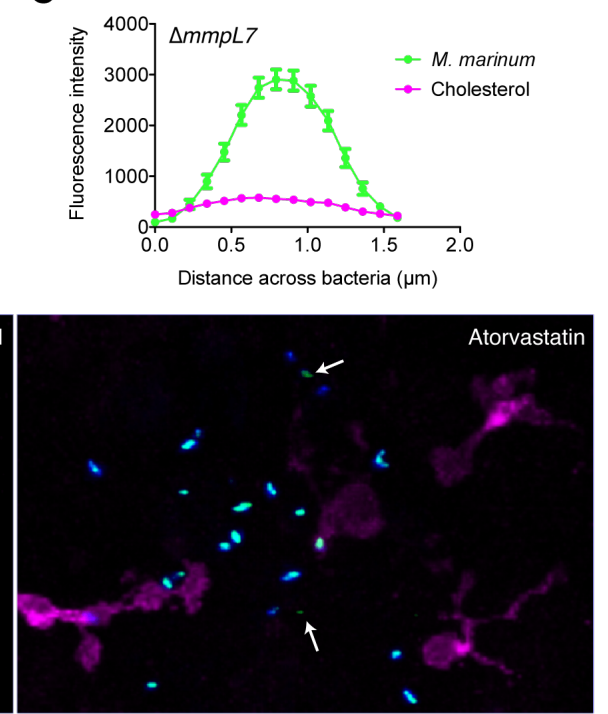

$\mathbf{H}$
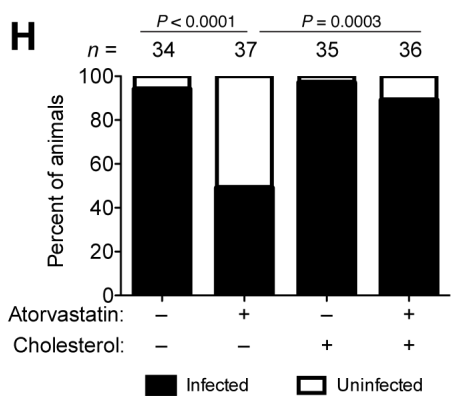

Figure 7. Cholesterol promotes PDIM spreading and mycobacterial infectivity. (A) Images of wildtype (WT) and $\triangle m m p L 7 M$. marinum expressing a green fluorescent protein following $48 \mathrm{~h}$ incubation with alkyne-cholesterol reacted with AlexaFlour647 Azide, scale bar $=3 \mu \mathrm{m}$. Mean $( \pm$ SEM) fluorescent intensity of line profiles drawn perpendicular to poles of (B) WT and (C) $\triangle m m p L 7 M$. marinum labeled as in A. (D) Mean cholesterol content of $3 \mathrm{dpf}$ zebrafish following a $24 \mathrm{~h}$ treatment with atorvastatin, water-soluble cholesterol, or both. Ordinary one-way ANOVA with Tukey's multiple comparisons test with selected adjusted $P$ values shown. (E) Images of

Atorvastatin: -+-+-+-+

$$
\text { MYD88: } \frac{++--}{\text { WT Mm }} \frac{++--}{\Delta m m p L 7 M m}
$$

control or atorvastatin treated transgenic fish whose macrophages express tdTomato at $2 \mathrm{hpi}$ with $\sim 100 \mathrm{M}$.
marinum expressing a cytosolic blue fluorescent protein reconstituted with DIBO-488 labeled azido-DIM (DIM-488), scale bar $=40 \mu \mathrm{m}$. Arrows, DIM-488 spread onto epithelial cells. (F) Mean percent DIM-488 in macrophage or epithelial cells not localized with bacteria at $2 \mathrm{~h}$ following HBV infection with $\sim 100 \mathrm{M}$. marinum in control or atorvastatin treated fish. Two-tailed, unpaired t test. (G) Mean bacterial volume following HBV infection of control or atorvastatin treated fish with $\sim 100 \mathrm{M}$. marinum. Two-tailed Mann Whitney test for $2 \mathrm{hpi}$ and two-tailed, unpaired t test for $24 \mathrm{hpi}$. $(\mathbf{H})$ Percentage of infected or uninfected fish at 3 dpi into the HBV with 1-3 wildtype M. marinum with or without atorvastatin and water-soluble cholesterol. (I) Percentage of infected or uninfected wildtype or MYD88-depleted fish at 3 dpi into the HBV with 1-3 wildtype or $\Delta$ $m m p L 7$ M. marinum with or without atorvastatin. (H) and (I) Fisher's exact test with Bonferroni's correction for multiple comparisons. (B)-(D) and (F)-(I) representative of three separate experiments.

343 sought to evaluate the role of statins in the reduction of bacterial burdens and in preventing 
344 infection. First, we showed that statin treatment reduced bacterial burdens in the zebrafish

345 (Figure 7G). Next, to evaluate if statins prevented infection, we infected zebrafish with 1-3

346 bacteria, similar to the infectious dose in humans (Bates et al., 1965; Wells et al., 1948), and

347 evaluated their ability to establish infection. This infectivity assay previously found that PDIM-

348 deficient M. marinum established infection at a reduced frequency (Cambier et al., 2017). We

349 treated zebrafish with atorvastatin for $24 \mathrm{~h}$ prior to infection with 1-3 bacteria and continued

350 daily atorvastatin treatment for the 3-day assay period. At $3 \mathrm{dpi}$, atorvastatin treatment decreased

351 wildtype M. marinum's infectivity by 50\% (Figure 7H). Moreover, restoring cholesterol levels

352 by co-treating with water-soluble cholesterol restored wildtype M. marinum's infectivity (Figure

$3537 \mathrm{H}$ ). This result confirmed atorvastatin reduces infectivity by lowering cholesterol rather than to

354 its other effects on physiology and metabolism. However, this protective low-cholesterol state

355 could be due to antimicrobial effects independent of PDIM spread. Altered cholesterol flux can

356 have pleotropic effects on immunity (Tall and Yvan-Charvet, 2015), and mycobacteria have been

357 shown to use cholesterol as a carbon source (Pandey and Sassetti, 2008).

358 To test the alternative hypothesis that atorvastatin's protection is not through disrupting

359 the PDIM-TLR axis we evaluated the infectivity of PDIM-deficient $\triangle m m p L 7$ M. marinum.

360 Consistent with previous reports (Cambier et al., 2017), $\Delta m m p L 7$ M. marinum exhibited

361 decreased infectivity compared to wildtype bacteria (Figure 7I). In agreement with our model

362 that atorvastatin acts through modulating PDIM spread, we found that atorvastatin treatment did

363 not further decrease $\Delta m m p L 7$ 's infectivity (Figure 7I). However, PDIM-deficient bacteria exhibit

364 such a severe virulence defect, any further attenuation due to other low-cholesterol-dependent

365 antimicrobial mechanisms may not be possible. To address this concern, we took advantage of

366 the fact that $\triangle m m p L 7$ 's virulence defect is reversed in the absence of host TLR signaling (Figure

367 7I, Cambier et al., 2014b). In this condition where PDIM-deficient bacteria are fully virulent,

368 they should become attenuated by any non-PDIM-associated antimicrobial mechanisms caused

369 by atorvastatin. However, atorvastatin still did not decrease $\triangle m m p L 7$ 's infectivity in MYD88-

370 depleted hosts (Figure 7I). Finally, we showed that atorvastatin decreased the infectivity of

371 wildtype M. marinum in a MYD88-dependent fashion (Figure 7I). These data strongly support

372 the idea that atorvastatin acts to disrupt the PDIM-TLR axis. Only in conditions where PDIM is

373 present on bacterial surfaces and when host TLR signaling is intact will lowering cholesterol

374 provide a protective effect. Collectively, these data demonstrate that statins reduce mycobacterial 
375 infectivity by reducing host cholesterol, and thereby PDIM's infiltration of epithelial

376 membranes.

\section{DISCUSSION}

Molecular Koch's postulates are a guiding set of principles used to characterize bacterial virulence factors (Falkow, 1988; 2004; Ramakrishnan, 2020). Genetic analyses are the mainstay of assigning pathogenic functions to specific virulence factors, including those not directly encoded by the genome. Virulence lipids are often assigned their pathogenic roles from studies of bacterial mutants lacking proteins involved in the lipid's biosynthesis or transport. Thus, these

384 functions can be directly attributed only to the biosynthetic protein, and not the lipid per se.

385 Here, by combining bioorthogonal chemistry with the zebrafish model of TB, we more rigorously satisfy molecular Koch's postulates to describe PDIM's role in virulence. PDIM's inherent fluidity and the abundance of cholesterol in epithelial membranes influenced PDIM's ability to infiltrate the host lipid environment. This occupation of epithelial membranes by PDIM mediated subversion of TLR signaling at the site of infection, thus enabling mycobacteria to gain access to non-activated immune cells (Figure 8).

The role epithelial cells play in priming innate immunity is appreciated in several models of bacterial pathogenesis. Pseudomonas aeruginosa and Staphylococcus aureus are both recognized by TLR-2 on human epithelial cells leading to the production of inflammatory cytokines (Soong et al., 2004). In zebrafish these responses result in bacterial clearance (Cambier et al., 2014b), highlighting this pathway as a conserved response to infection. In contrast, human epithelial cells infected by mycobacteria have no significant change in global transcription, suggesting minimal immune detection (Reuschl et al., 2017). Our data now demonstrate that PDIM plays a role in silencing epithelial cell responses, promoting uptake by non-activated macrophages.

402 PDIM-expressing mycobacteria were rendered growth-attenuated if co-infected with TLR-

403 stimulating bacteria (Cambier et al., 2014b). While our current model suggests a more active role 404 for PDIM, we still find that TLR-stimulating bacteria cause attenuation of wildtype bacteria.

405 Specifically, bacteria unable to spread PDIM caused attenuation of bacteria that can spread 


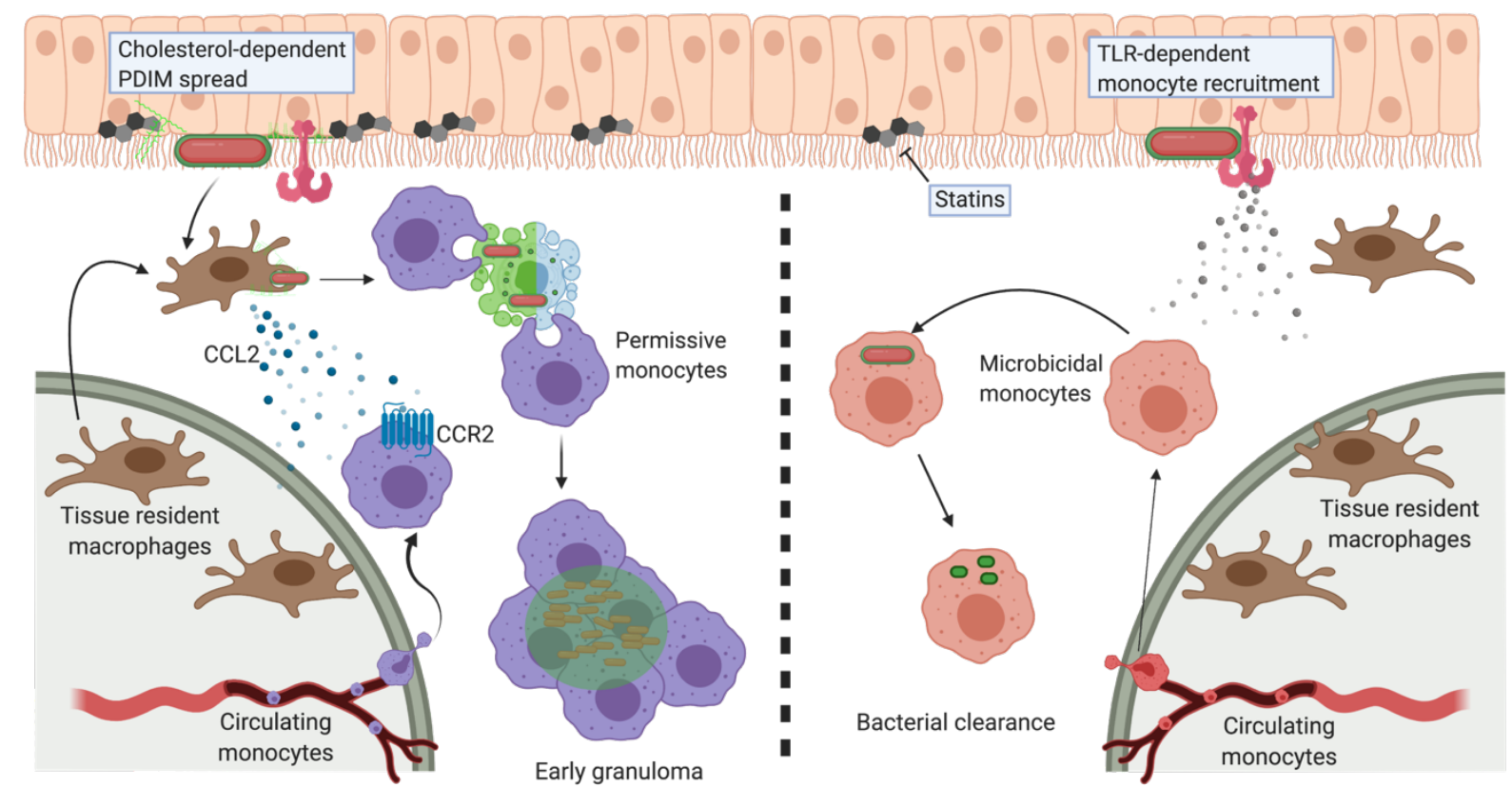

Figure 8. Model of PDIM spreading to promote virulence. Cholesterol-dependent PDIM spread into epithelial membranes prevents TLR detection at the site of infection. Bacteria then drive resident macrophages to produce CCL2 to recruit CCR2-positive permissive monocytes which go on to form early granulomas. PDIM continues to spread into host membranes throughout this process. In low cholesterol settings (statin treatment) PDIM does not spread as readily into epithelial membranes. TLR-dependent recruitment of microbicidal monocytes occurs, which can then clear infecting mycobacteria.

407 PDIM (Figure 6B and C). These findings argue that PDIM's influence over innate immune 408 signaling is spatially restricted. PDIM appears to only inhibit TLR signaling at membrane sites 409 where it has spread, emphasizing the need for PDIM localization on the bacterial surface prior to 410 spreading into epithelial membranes. Once spread, the potential for PDIM to disrupt membrane 411 protein signaling is intriguing. Several biophysical properties of membranes are known to 412 mediate membrane protein function (Los and Murata, 2004), and PDIM has been implicated in 413 altering host membrane structure (Augenstreich et al., 2019). Furthermore, TLRs have been 414 shown to aggregate into cholesterol rich lipid domains to facilitate downstream signaling events 415 (Ruysschaert and Lonez, 2015). How PDIM's affinity for cholesterol promotes spread and 416 whether this association disrupts TLR-cholesterol lipid domains is yet to be determined. The finding that PDIM's methyl-branched mycocerosic acids are required for virulence

418 suggests pathogenic mycobacteria have evolved a lipid-based immunomodulatory strategy 419 similar to that seen at host barrier tissues. While predominant across prokaryotes, methyl420 branched fatty acids are only found in certain secretions of higher eukaryotes. In particular, 421 vernix caseosa, a white wax that covers neonates during the third trimester of gestation, is 
422 implicated in promoting normal gut development and microbial colonization (Nishijima et al.,

423 2019). The fetus swallows a significant amount of vernix shed in the amniotic fluid, in increasing

424 amounts as term birth approaches. Premature infants are exposed to substantially less vernix and

425 have increased rates of necrotizing enterocolitis (Ran-Ressler et al., 2011). In a rat model of

426 necrotizing enterocolitis, feeding premature pups methyl-branched lipids led to a decrease in

427 disease development and a shift from a pro-inflammatory to an anti-inflammatory gut

428 environment (Ran-Ressler et al., 2011). These studies implicate lipid-based immunomodulation

429 as playing a key role in tissue-barrier homeostasis, dampening immune responses to allow for

430 proper microbial colonization. Mycobacteria appear to have adapted this strategy of using

431 methyl-branched lipids as an immunomodulatory mechanism to establish infection and thereby

432 ensure their evolutionary survival.

433 Systemic cholesterol metabolism in humans influences the lung environment, including

434 the abundance of cholesterol in lung epithelial membranes (Fessler, 2017). Therefore,

435 cholesterol-promoted PDIM spreading may also influence M. tuberculosis transmission. While a

436 clinical trial is currently underway evaluating the use of statins alongside standard TB therapy

437 (Karakousis et al., 2019), our data instead argue for the use of statins as a TB preventative

438 therapy.

\section{ACKNOWLEDGEMENTS}

We thank Lalita Ramakrishnan for help interpreting data and manuscript writing, Karen

443 David Tobin for zebrafish lines. This work was supported by a National Institutes of Health grant

444 (AI51622) to C.R.B. C.J.C. was supported by a Damon Runyon Postdoctoral Fellowship. S.M.B

445 and J.A.B were supported by NIGMS F32 Postdoctoral Fellowships.

\section{AUTHOR CONTRIBUTIONS}




\section{DECLARATION OF INTERESTS}

454 C.R.B. is a co-founder of OliLux Bio, Palleon Pharmaceuticals, InverVenn Bio, Enable

455 Biosciences, and Lycia Therapeutics, and member of the Board of Directors of Eli Lilly. 


\section{MATERIALS AND METHODS}

485 RESOURCES TABLE

\begin{tabular}{|c|c|c|}
\hline REAGENT or RESOURCE & SOURCE & IDENTIFIER \\
\hline \multicolumn{3}{|l|}{ Bacterial and Virus Strains } \\
\hline $\begin{array}{l}\text { Mycobacterium marinum M strain transformed with } \\
\text { pMS12:tdTomato, pMS12:EBFP2, or pMS12:wasabi }\end{array}$ & Takaki et al., 2013. & $\begin{array}{l}\text { derivative of ATCC } \\
\text { \#BAA-535 }\end{array}$ \\
\hline $\begin{array}{l}\Delta m m p L 7 \text { Mycobacterium marinum M strain transformed } \\
\text { with pMS12:tdTomato or pMS12:wasabi }\end{array}$ & Cambier et al., 2014b. & NA \\
\hline $\begin{array}{l}\text { Top10 Escherichia coli transformed with pBAD:tret from } \\
\text { Thermoproteus tenax }\end{array}$ & Urbanek et al., 2014. & NA \\
\hline \multicolumn{3}{|l|}{ Chemicals, Peptides, and Recombinant Proteins } \\
\hline Iodotrimethylsilane & ACROS & $\begin{array}{l}\text { Cat\#10530964 } \\
\text { CAS:16029-98-4 }\end{array}$ \\
\hline Sodium azide & Sigma-Aldrich & $\begin{array}{l}\text { Cat\#S8032 } \\
\text { CAS: } 26628-22-8\end{array}$ \\
\hline Tetrabutylammonium hydroxide solution & Sigma-Aldrich & $\begin{array}{l}\text { Cat\#178780 } \\
\text { CAS: } 2052-49-5\end{array}$ \\
\hline Lignoceric acid & Sigma-Aldrich & $\begin{array}{l}\text { Cat\# L6641 } \\
\text { CAS: } 557-59-5\end{array}$ \\
\hline Click-IT Alexa Fluor 488 DIBO Alkyne & Thermo-Fisher & $\begin{array}{l}\text { Cat\# C10405 } \\
\text { Discontinued* }\end{array}$ \\
\hline Click-IT Alexa Fluor 647 DIBO Alkyne & Thermo-Fisher & $\begin{array}{l}\text { Cat\# C10408 } \\
\text { Discontinued* }\end{array}$ \\
\hline Alexa Fluor 647 Azide & Thermo-Fisher & Cat\# A10277 \\
\hline Alkyne Cholesterol & Click Chemistry Tools & Cat\# 1409 \\
\hline 6-azido-6-deoxy-glucose & Sigma-Aldrich & $\begin{array}{l}\text { Cat\# 712760 } \\
\text { CAS: } 20847-05-6\end{array}$ \\
\hline UDP-glucose & Sigma-Aldrich & $\begin{array}{l}\text { Cat\# U4625 } \\
\text { CAS: } 28053-08-9\end{array}$ \\
\hline Alexa-647 hydroxylamine & Thermo-Fisher & Cat\# A30632 \\
\hline Methyl-ß-cyclodextrin & Sigma-Aldrich & $\begin{array}{l}\text { Cat\# C4555 } \\
\text { CAS: } 128446-36-6\end{array}$ \\
\hline Cholesterol-water soluble & Sigma-Aldrich & Cat\# C4951 \\
\hline Atorvastatin & Sigma-Aldrich & Cat\# PHR1422 \\
\hline Methylene blue & Sigma-Aldrich & $\begin{array}{l}\text { Cat\# M9140 } \\
\text { CAS: } 122965-43-9\end{array}$ \\
\hline Tango Buffer (10x) & Thermo-Fisher & Cat\#BY5 \\
\hline Phenol Red Sodium Salt & Sigma-Aldrich & $\begin{array}{l}\text { Cat\#P4758 } \\
\text { CAS: } 34487-61-1\end{array}$ \\
\hline PMA (Phorbol 12-myristate 13-acetate) & Sigma-Aldrich & $\begin{array}{l}\text { Cat\#P1585 } \\
\text { CAS:16561-29-8 }\end{array}$ \\
\hline Hygromycin B & Thermo-Fisher & Cat\#10687010 \\
\hline Glutaraldehyde solution ( $70 \%$ in water) & Sigma-Aldrich & $\begin{array}{l}\text { Cat\#G7776 } \\
\text { CAS: } 111-30-8\end{array}$ \\
\hline $16 \%$ paraformaldehyde solution & Thermo-Fisher & Cat\#28908 \\
\hline BTTP & Click Chemistry Tools & $\begin{array}{l}\text { Cat\#1414 } \\
\text { CAS: } 1334179-85-9\end{array}$ \\
\hline
\end{tabular}




\begin{tabular}{|c|c|c|}
\hline $\begin{array}{l}\text { Total Cholesterol and Cholesterol Ester } \\
\text { Colorimetric/Fluorometric Assay Kit }\end{array}$ & Bio-Vision & Cat\# K603 \\
\hline \multicolumn{3}{|l|}{ Experimental Models: Cell Lines } \\
\hline A549 human alveolar epithelial cells & ATCC & CCL-185 \\
\hline THP-1 human monocytic cell line & ATCC & TIB-202 \\
\hline \multicolumn{3}{|l|}{ Experimental Models: Organisms/Strains } \\
\hline Zebrafish (Danio rerio) wild type $A B$ strain & Stanford University & $\begin{array}{l}\text { ZFIN ID: ZDB- } \\
\text { GENO-960809-7 }\end{array}$ \\
\hline Zebrafish: Tg(mfap4:tdTomato) & Walton et al., 2015. & $\begin{array}{l}\text { ZFIN ID: ZDB- } \\
\text { TGCONSTRCT- } \\
160122-3\end{array}$ \\
\hline \multicolumn{3}{|l|}{ Oligonucleotides } \\
\hline $\begin{array}{l}\text { myD88 morpholino sequence: } \\
\text { GTTAAACACTGACCCTGTGGATCAT }\end{array}$ & Bates et al., 2007. & $\begin{array}{l}\text { ZFIN ID: ZDB- } \\
\text { MRPHLNO-080325- } \\
4\end{array}$ \\
\hline \multicolumn{3}{|l|}{ Software and Algorithms } \\
\hline NIS-Elements & Nikon & \\
\hline Imaris & Bitplane & \\
\hline Prism & GraphPad & \\
\hline
\end{tabular}

486 *Since preparing this manuscript we have found that AFDye 488 DBCO (Click Chemistry Tools, 487 Cat\# 1278) and AFDye 647 DBCO (Click Chemistry Tools, Cat\# 1302) are suitable alternatives 488 to the DIBO fluorophores. The DBCO dyes can be used with the same concentrations and 489 labeling protocols presented in this manuscript for the DIBO dyes (Unpublished data).

491 Procedures and materials for synthetic chemistry: All reactions were performed in dry

492 standard glassware fitted with rubber septa under an inert atmosphere of nitrogen unless

493 otherwise stated. Preparative thin-layer chromatography (TLC) was performed with Millipore's

$4941 \mathrm{~mm}$ and $0.2 \mathrm{~mm}$ silica gel 60 pre-coated glass plates. Analytical TLC was used for reaction 495 monitoring and product detection using pre-coated glass plates covered with $0.20 \mathrm{~mm}$ silica gel

496 with fluorescent indicator; visualized by UV light and 10\% CuSO4 in 1.3M phosphoric acid in

497 water. Reagents were purchased in reagent grade from commercial suppliers and used as

498 received, unless otherwise described. Anhydrous dichloromethane (DCM) was prepared by

499 passing the solvent through an activated alumina column.

501 Chemical Analysis Instrumentation: Proton $\left({ }^{1} \mathrm{H}\right.$ NMR $)$ and proton-decoupled carbon-13 $\left({ }^{13} \mathrm{C}\right.$

$\left.502\left\{{ }^{1} \mathrm{H}\right\} \mathrm{NMR}\right)$ nuclear magnetic resonance spectra were recorded on an Inova-500 spectrometer at $50325^{\circ} \mathrm{C}$, are reported in parts per million downfield from tetramethylsilane, and are referenced to 504 the residual protium $\left(\mathrm{CDCl}_{3}: 7.26\left[\mathrm{CHCl}_{3}\right]\right)$ and carbon $\left(\mathrm{CDCl}_{3}: 77.16\right)$ resonances of the $\mathrm{NMR}$ 
505

506

507

508

509

510

\section{1}

512 solvent. Data are represented as follows: chemical shift, multiplicity $(\mathrm{br}=$ broad, $\mathrm{s}=$ singlet, $\mathrm{d}=$ doublet, $\mathrm{t}=$ triplet, $\mathrm{q}=$ quartet, quin = quintet, $\mathrm{sept}=$ septet, $\mathrm{m}=$ multiplet), coupling constants in Hertz (Hz), integration. Mass spectra were obtained on a Bruker Microflex MALDI-TOF by mixing $0.5 \mu \mathrm{l}$ of $1 \mathrm{mg} / \mathrm{ml}$ sample in chloroform with $0.5 \mu \mathrm{l}$ of $10 \mathrm{mg} / \mathrm{ml} 2,5$-dihydroxybenzoic acid before spotting onto a 96-well MALDI plate.

\section{Isolation of PDIM}

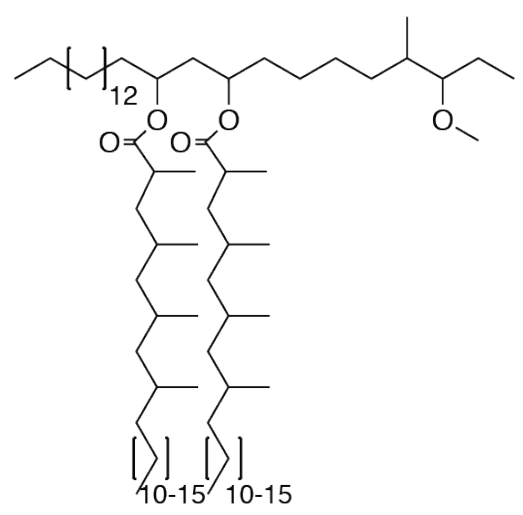

Wildtype M. marinum was grown in GAS medium without Tween-80 to an $\mathrm{OD}_{600}$ of 1.2 .

Bacteria were pelleted, frozen and lyophilized on a Labconoco FreezeZone 4.5 plus. Bacterial lipids were then extracted by stirring lyophilized pellet in petroleum ether for $1 \mathrm{~h}$ at $23{ }^{\circ} \mathrm{C}$.

Bacteria were allowed to settle, and solvent was collected. Remaining bacteria were re-extracted 3-5 times. The solvent extract was then passed through a $0.2 \mu \mathrm{m}$ PTFE filter, and crude lipids were concentrated under reduced pressure. Crude lipid extracts were separated by preparative TLC in the solvent system 98:2 petroleum ether:ethyl acetate. The band correlating to PDIM at an $\mathrm{Rf}=0.4$ was isolated. Preparative TLC was repeated twice more to further purify PDIM. Average PDIM isolated from M. marinum was 60mg per 10 liters of culture. ${ }^{1} \mathrm{H}$ NMR (500 $\left.\mathrm{MHz}, \mathrm{CDCl}_{3}\right) \delta$ 4.93-4.87 (m, 2H), $3.32(\mathrm{~s}, 3 \mathrm{H}), 2.87-2.83(\mathrm{~m}, 1 \mathrm{H}), 2.57-2.51(\mathrm{~m}, 2 \mathrm{H}), 1.90-0.81$ (m, 166H). ${ }^{13} \mathrm{C}$ NMR $\left(126 \mathrm{MHz}, \mathrm{CDCl}_{3}\right) \delta 176.69,176.63,86.78,86.73,77.41,77.37,77.16$, 76.90, 70.72, 70.67, 57.51, 45.56, 45.51, 41.41, 41.33, 38.56, 37.85, 37.73, 37.09, 36.77, 34.91, $34.18,34.07,32.83,32.08,30.24,29.96,29.87,29.82,29.75,29.62,29.53,28.34,27.64,27.36$, 27.25, 27.16, 27.12, 25.74, 25.35, 22.85, 22.74, 22.43, 20.81, 20.57, 20.52, 20.37, 20.27, 18.67, 18.58, 18.53, 14.80, 14.75, 14.28, 14.22, 10.26, 1.16. MALDI-TOF for: C82H162O5 Calc'd 
$530\left[\mathrm{M}+\mathrm{Na}^{+}\right]=1250.23$; found 1250.41. C84H166O5 Calc'd $\left[\mathrm{M}+\mathrm{Na}^{+}\right]=1278.26$, found 1278.40.

$531 \quad \mathrm{C} 86 \mathrm{H} 170 \mathrm{O} 5 \mathrm{Calc}{ }^{\prime} \mathrm{d}\left[\mathrm{M}+\mathrm{Na}^{+}\right]=1306.29$, found 1306.55.

532

533

\section{Synthesis of azido-DIM}

534
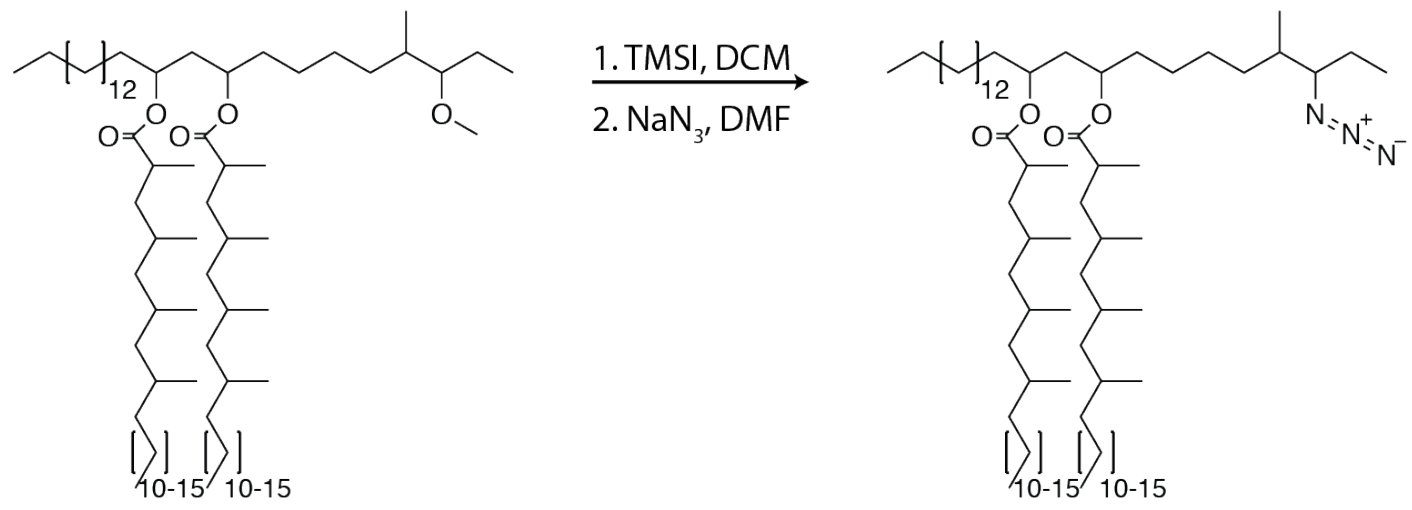

536

To PDIM (75.6mg, $60.2 \mu \mathrm{mol}, 1.0$ equiv.) was added $0.3 \mathrm{ml}$ of DCM, the mixture was stirred and iodotrimethylsilane (TMSI, $258 \mu 1,1.8 \mathrm{mmol}, 30.0$ equiv.) was added and allowed to react for 12 h at $23{ }^{\circ} \mathrm{C}$. The reaction was concentrated under reduced pressure. NaN3 $(39.1 \mathrm{mg}, 602 \mu \mathrm{mol}$, 10.0 equiv.) was added followed by $0.3 \mathrm{ml}$ of anhydrous dimethylformamide (DMF) and stirred

541 for $12 \mathrm{~h}$ at $23{ }^{\circ} \mathrm{C}$. The solvent was removed under reduced pressure and the product was purified

542 using preparative TLC in $98: 2$ petroleum ether:ethyl acetate $\mathrm{Rf}=0.5$ as a white wax $(37.7 \mathrm{mg}$, $54329.8 \mu \mathrm{mol}, 50 \%) .{ }^{1} \mathrm{H}$ NMR $\left(500 \mathrm{MHz} \mathrm{CDCl}_{3}\right) \delta 5.06-4.86(\mathrm{~m}, 2 \mathrm{H}), 3.30-3.21(\mathrm{~m}, 1 \mathrm{H}), 2.58-2.50$ $544(\mathrm{~m}, 2 \mathrm{H}) 2.1-0.81(\mathrm{~m}, 163 \mathrm{H}) .{ }^{13} \mathrm{C} \mathrm{NMR}\left(126 \mathrm{MHz}, \mathrm{CDCl}_{3}\right) \delta 176.73,176.63,77.41,77.36,77.16$, $54576.91,71.08,70.74,59.86,45.56,41.96,41.45,41.35,39.27,37.84,37.73,37.24,37.08,37.01$, $54635.28,34.82,34.18,32.08,30.32,30.24,30.22,30.04,29.96,29.87,29.82,29.75,29.72,29.67$, $54729.62,29.52,29.39,28.40,28.34,27.72,27.36,27.25,27.18,27.16,26.20,25.35,25.27,25.23$, $548 \quad 22.85,21.28,21.13,20.35,20.32,20.27,18.73,18.66,18.58,18.53,14.56,14.29,13.87$.

549 MALDI-TOF for: C81H159N3O4 Calc'd $\left[\mathrm{M}+\mathrm{Na}^{+}\right]=1261.22$; found 1260.92. C83H163N3O4 550 Calc'd $\left[\mathrm{M}+\mathrm{Na}^{+}\right]=1289.25$, found 1289.02. C85H167N3O4 Calc'd $\left[\mathrm{M}+\mathrm{NH} 4^{+}\right]=1312.33$, found $551 \quad 1312.37$. 


\section{Hydrolysis of PDIM and isolation of phthiocerol}

556

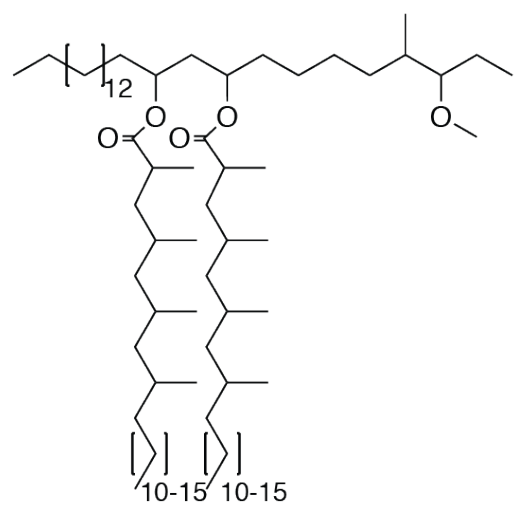

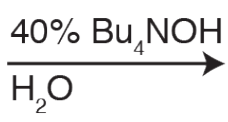<smiles>CCCCCCCC(O)CC(O)CCCCC(C)C(CC)OC</smiles>

To dried PDIM $(66.7 \mathrm{mg}, 53.1 \mu \mathrm{mol})$ was added $0.5 \mathrm{ml}$ of $40 \%$ tetrabutylammonium hydroxide in water, the mixture was sealed, aggressively stirred, and allowed to react for $48 \mathrm{~h}$ at $120^{\circ} \mathrm{C}$. Reaction was cooled to $23{ }^{\circ} \mathrm{C}$ and $4 \mathrm{M}$ HCL was added dropwise until $\mathrm{pH}$ was $<3$. The reaction was extracted with DCM and washed once with water. The solvent was removed under reduced pressure and phthiocerol was purified using preparative TLC in 80:20 petroleum ether:ethyl acetate $\mathrm{Rf}=0.4 .(18.8 \mathrm{mg}, 42.5 \mu \mathrm{mol}, 80 \%) .{ }^{1} \mathrm{H} \mathrm{NMR}\left(500 \mathrm{MHz}, \mathrm{CDCl}_{3}\right)$ and ${ }^{13} \mathrm{C} \mathrm{NMR}(126$ $\mathrm{MHz}, \mathrm{CDCl}_{3}$ ) matched previously reported spectra. ESI HRMS for: C28H58O3 Calc'd $\left[\mathrm{M}+\mathrm{H}^{+}\right]=443.4464$; found 443.4449. C29H60O3 Calc'd $\left[\mathrm{M}+\mathrm{H}^{+}\right]=457.4621$; found 457.4616.

\section{Synthesis of PDIF}


573 To phthiocerol (18.8mg, 42.5 $4 \mathrm{~mol}, 1$ equiv.) was added lignoceric acid (47mg, $127.5 \mu \mathrm{mol}, 3.0$

574 equiv.), N,N'-dicyclohexylcarbodiimide (DCC, 35mg, 170 $\mu \mathrm{mol}, 4.0$ equiv.), 4-

575 Dimethylaminopyridine (DMAP, $20.77 \mathrm{mg}, 170 \mu \mathrm{mol}, 4.0$ equiv.), and $2.3 \mathrm{ml}$ of DCM. The

576 reaction was stirred and allowed to react for $16 \mathrm{~h}$ at $23{ }^{\circ} \mathrm{C}$. The solvent was removed under

577 reduced pressure and the product was purified using preparative TLC in 98:2 petroleum

578 ether:ethyl acetate $\mathrm{Rf}=0.4$. (12.8mg, $11.5 \mu \mathrm{mol}, 27 \%) .{ }^{1} \mathrm{H} \mathrm{NMR}\left(500 \mathrm{MHz}, \mathrm{CDCl}_{3}\right) \delta 4.94-4.87$

579 (quin, 2H), $3.33(\mathrm{~s}, 3 \mathrm{H}), 2.88-2.83(\mathrm{~m}, 1 \mathrm{H}), 2.30-2.25(\mathrm{t}, 4 \mathrm{H}), 1.75-0.79(\mathrm{~m}, 141 \mathrm{H}) .{ }^{13} \mathrm{C} \mathrm{NMR}$

$580 \quad\left(126 \mathrm{MHz} \mathrm{CDCl}_{3}\right) \delta 173.42,86.66,77.27,77.02,76.76,70.97,57.40,38.45,34.84,34.67$,

$58134.13,34.09,32.62,31.94,29.73,29.68,29.55,29.47,29.38,29.34,29.23,27.44,25.57,25.17$,

582 25.10, 22.70, 22.37, 14.76, 14.12, 10.10. MALDI-TOF for: C76H150O5 Calc'd

$583\left[\mathrm{M}+\mathrm{Na}^{+}\right]=1166.14$, found 1166.14. C77H152O5 Calc'd $\left[\mathrm{M}+\mathrm{Na}^{+}\right]=1180.15$, found 1180.24.

\section{Synthesis of azido-DIF}

587
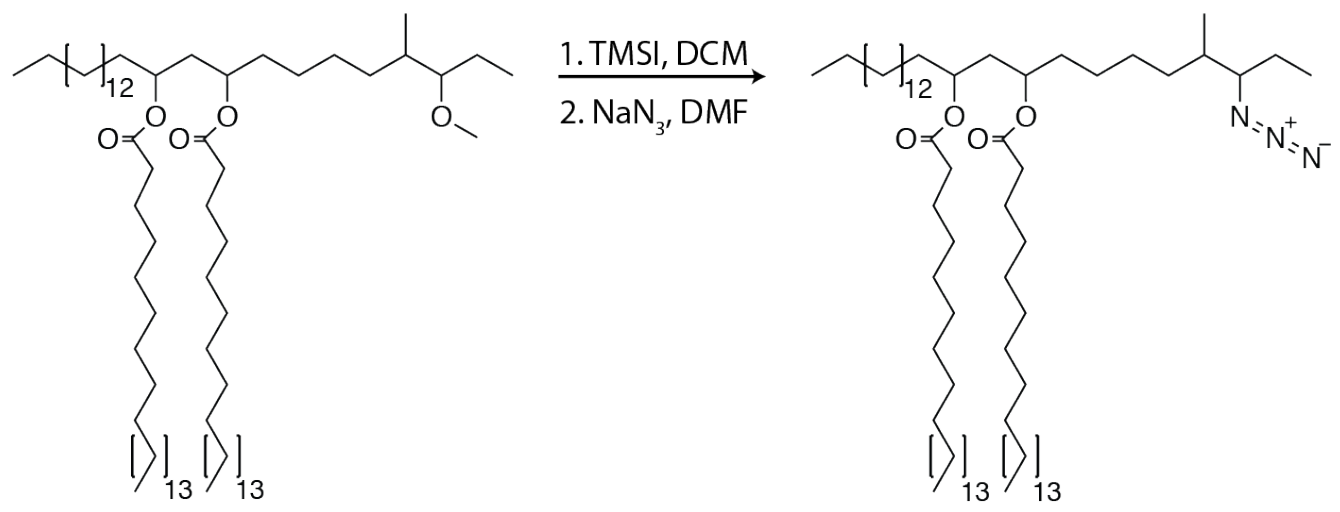

590 To PDIF (12.8mg, $11.5 \mu \mathrm{mol}, 1$ equiv.) was added $0.3 \mathrm{ml}$ of DCM, the mixture was stirred and

591 TMSI ( $49 \mu 1,345 \mu \mathrm{mol}, 30.0$ equiv.) was added and allowed to react for $3 \mathrm{~h}$ at $23^{\circ} \mathrm{C}$. The reaction

592 was concentrated under reduced pressure. $\mathrm{NaN}_{3}(7.5 \mathrm{mg}, 115 \mu \mathrm{mol}, 10.0$ equiv.) was added

593 followed by $0.3 \mathrm{ml}$ of anhydrous dimethylformamide (DMF) and stirred for $12 \mathrm{~h}$ at $23{ }^{\circ} \mathrm{C}$. The

594 solvent was removed under reduced pressure and the product was purified using preparative TLC

595 in 98:2 petroleum ether:ethyl acetate $\mathrm{Rf}=0.5$. (6.9mg, $6 \mu \mathrm{mol}, 52 \%) .{ }^{1} \mathrm{H} \mathrm{NMR}\left(500 \mathrm{MHz}, \mathrm{CDCl}_{3}\right)$

$596 \delta 5.08-5.00(\mathrm{~m}, 2 \mathrm{H}), 3.32-3.20(\mathrm{~m}, 2 \mathrm{H}), 3.12-3.04(\mathrm{~m}, 1 \mathrm{H}), 2.33-2.25(\mathrm{t}, 4 \mathrm{H}), 1.80-0.73(\mathrm{~m}$,

597 138H). ${ }^{13} \mathrm{C}$ NMR (126 MHz, $\left.\mathrm{CDCl}_{3}\right) \delta 173.41,77.27,77.02,76.76,71.16,70.05$, 59.72, 39.09, 
$36.92,35.12,34.70,34.64,32.34,31.94,29.72,29.67,29.58,29.53,29.42,29.38,29.33,29.23$, 26.05, 25.15, 24.02, 22.70, 21.15, 16.10, 14.13, 11.06, 1.03. ESI C75H148NO4 calc'd [M+K, $\left.\mathrm{N}_{2}\right]=1166.10$, found 1166.05 .

\section{Zebrafish Husbandry and Infections}

603 Wild-type AB (Zebrafish International Resource Center), and Tg(mfap4:tdTomato) (Walton et 604 al., 2015) lines were maintained in buffered reverse osmotic water systems. Fish were fed twice 605 daily a combination of dry feed and brine shrimp and were exposed to a $14 \mathrm{~h}$ light, $10 \mathrm{~h}$ dark cycle to maintain proper circadian conditions. Zebrafish embryos were maintained at $28.5^{\circ} \mathrm{C}$ in embryo media which consisted of the following dissolved in Milli-Q water (\%weight/volume): 0. 0875\% sodium chloride, $0.00375 \%$ potassium chloride, $0.011 \%$ calcium chloride, $0.00205 \%$ monopotassium phosphate, $0.00089 \%$ disodium phosphate, and $0.0493 \%$ magnesium sulfate.

610 Embryo media was then buffered to $\mathrm{pH} 7.2$ with sodium bicarbonate. Embryos were maintained 611 in $0.25 \mathrm{mg} / \mathrm{ml}$ methylene blue (Sigma) from collection to 1-day post-fertilization (dpf). $0.003 \%$

612 PTU (1-phenyl-2-thiourea, Sigma) was added from $24 \mathrm{~h}$ post-fertilization (hpf) on to prevent

613 pigmentation. Larvae (of undetermined sex given the early developmental stages used) were

614 infected at $48 \mathrm{hpf}$ via the hindbrain ventricle (HBV) using single-cell mycobacterial suspensions

615 of known titer. Number of animals to be used for each experiment was guided by pilot

616 experiments or by past results with other bacterial mutants and/or zebrafish. On average 15 to 40

617 larvae per experimental condition were required to reach statistical significance and each

618 experiment was repeated at least three times. Larvae were randomly allotted to the different

619 experimental conditions. The zebrafish husbandry briefly described above and all experiments

620 performed on them were in compliance with the U.S. National Institutes of Health guidelines and 621 approved by the Stanford Institutional Animal Care and Use Committee.

\section{Bacterial Strains and Methods}

624 M. marinum strain M (ATCC BAA-535) and $\Delta m m p L 7$ mutants (Cambier et al., 2014b)

625 expressing either TdTomato, Wasabi, or EBFP2 under the control of the msp12 promoter were 626 grown under hygromycin (Thermo-Fisher) selection in 7H9 Middlebrook's medium (Difco) 627 supplemented with 10\% OADC (Fisher), 0.2\% glycerol, and 0.05\% Tween-80 (Sigma). Where 
629 (\%weight/volume) in 18mM sodium hydroxide in Milli-Q water $\mathrm{pH} 6.6$ +/- 0.05\% Tween-80:

$630 \quad 0.03 \%$ BactoCasitone (BD Science), 0.005\% ferric ammonium citrate (Sigma), 0.4\% potassium

631 phosphate dibasic anhydrous (VWR), 0.2\% citric acid, anhydrous (VWR), 0.1\% L-alanine

632 (Sigma), 0.12\% magnesium chloride, heptahydrate (VWR), 0.06\% potassium sulfate (VWR),

$6330.2 \%$ ammonium chloride (VWR), and 1\% glycerol. To prepare heat-killed M. marinum, bacteria

634 were incubated at $80^{\circ} \mathrm{C}$ for $20 \mathrm{~min}$. To prepare fixed bacteria, bacteria were incubated in

635 described concentrations of glutaraldehyde (Sigma) and/or paraformaldehyde (Thermo-Fisher)

636 for $1 \mathrm{hr}$ at $23^{\circ} \mathrm{C}$, followed by 3 washes with PBS prior to experimental use.

\section{Cell Lines and infections}

639 Cells were grown in T75 flasks (Thermo-Fisher) and maintained at $37{ }^{\circ} \mathrm{C}$ and $5 \%$ CO2. THP-1

640 were grown in RPMI supplemented with 10\% fetal bovine serum (FBS). A549 were grown in

641 DMEM supplemented with 10\% FBS. Two days prior to infection, THP-1s were plated on 8-

642 well Nunc Lab-Tek II chamber slides (Thermo-Fisher) at a density of 150,000 cells per well with

643 100nM PMA (phorbol 12-myristate 13-acetate, Sigma) in growth media and incubated at $37^{\circ} \mathrm{C}$

644 and 5\% CO2 for $24 \mathrm{~h}$. One day prior to infection, the media on THP-1s was replaced with fresh

645 growth media and the cells were incubated at $33^{\circ} \mathrm{C}$ and $5 \% \mathrm{CO} 2$ for $24 \mathrm{~h}$, cells were then

646 infected with M. marinum at a multiplicity of infection (MOI) of 2 in growth media. Infection

647 was allowed to progress for $6 \mathrm{~h}$ prior to washing twice with PBS and replacing with growth

648 media. THP-1s were then incubated for $24 \mathrm{~h}$ at $33^{\circ} \mathrm{C}$ and $5 \% \mathrm{CO} 2$ prior to experimental end

649 point. One day prior to infection, A549s were plated on 8-well chamber Nunc Lab-Tek II

650 chamber slides (Thermo-Fisher) at a density of 50,000 cells per well in growth media and

651 incubated at $37^{\circ} \mathrm{C}$ and $5 \% \mathrm{CO} 2$. Day of infection cells were moved to $33^{\circ} \mathrm{C}$ and $5 \% \mathrm{CO} 2$ for $3 \mathrm{~h}$,

652 and then were infected with $M$. marinum at a MOI of 5 and incubated at $33^{\circ} \mathrm{C}$ and $5 \% \mathrm{CO} 2$ for

$65324 \mathrm{~h}$. Infected THP-1s and A549s were then imaged as described below.

\section{Extraction and reconstitution of M. marinum}

656 Extraction. 1 liter of M. marinum were grown in GAS medium plus Tween-80 to an $\mathrm{OD}_{600}$ of

657 1.2. Bacteria were pelleted in a glass $50 \mathrm{~mL}$ conical tubes (Fisher) of known weight, frozen and

658 lyophilized. The dry bacteria in $50 \mathrm{~mL}$ conical tubes were then weighed and the dry bacterial

659 weight was calculated. $25 \mathrm{~mL}$ of petroleum ether were then added to the bacteria, and the conical 
660 tube was capped with a PTFE lined lid (Sigma) and the suspension was vortexed for 3min. An

661 additional $25 \mathrm{~mL}$ of petroleum ether was added and the sample was centrifuged for $3 \mathrm{~min}$ at

$6621000 \mathrm{xg}$ at $4^{\circ} \mathrm{C}$. The extract was then saved or discarded depending on the downstream

663 experimental applications and the bacteria were extracted once more as above. For total lipid

664 extractions (not used for reconstitution), bacteria were treated with 1:1 chloroform:methanol for

$66512 \mathrm{~h}$ at $60^{\circ} \mathrm{C}$. Extracts were filtered, back extracted with water to remove water soluble

666 contaminants, dried under reduced pressure and used for downstream experiments.

Reconstitution. Prior to extractions the following calculation was used to determine the amount

669 of lipids to add back to each pellet.

673 Where $23 \mathrm{mg}$ of lipid per gram of dry bacteria is the experimentally determined average amount

674 of lipid removed during petroleum ether extraction of bacteria grown in these conditions (Figure

$675 \mathrm{~S} 1 \mathrm{~B}$, initial extraction) and the 0.75 reconstitution efficiency was also experimentally determined

676 (Figure S1C). If reconstituting with DIM variants, 30\% of the above weight consists of DIMs

677 and the remainder will consist of DIM-depleted petroleum ether lipid extracts. Following two

678 rounds of petroleum ether extraction as detailed above, bacteria were immediately mixed with

679 pre-determined lipid mixtures (or no lipid at all for delipidated bacteria) in petroleum ether (2-3

$680 \mathrm{mls}$ ) followed by extended drying under reduced pressure. Dried bacteria were then rescued into

$6817 \mathrm{H} 9$ media supplemented with 10\% OADC, and 0.2\% glycerol (prep media) and subjected to

682 single cell preparation protocol.

683

\section{M. marinum single cell preparation}

685 For more thorough details, as well as rationale and explanation of the following protocol see

686 Takaki et al., 2013. Bacteria were washed once with $15 \mathrm{~mL}$ of prep media followed by

687 resuspension in $500 \mu 1$ of prep media. Bacteria were then passed through a 27-gauge needle 10 688 times, followed by the addition of $1 \mathrm{ml}$ of prep media and centrifugation at $100 \mathrm{xg}$ for $3 \mathrm{~min} .1 \mathrm{ml}$

689 of supernatants were saved. This process was repeated 3-5 times. Collected supernatants were 690 then passed through a 5.0 $\mu \mathrm{m}$ acrodisc versapor membrane syringe filter (VWR). The filtrate was 
691 then pelleted at $16,000 \mathrm{xg}$ for $2 \mathrm{~min}$, pellets were resuspended in prep media to a concentration of

692 around $1 \times 10^{\wedge} 8-9$ bacteria per $\mathrm{ml}$, aliquoted and stored at $-20 \mathrm{C}$ for future use, or immediately

693 subjected to copper-free click chemistry reactions.

\section{Metabolic labeling of $M$. marinum with 6-TreAz}

Expression and Purification of TreT: TreT was expressed and purified utilizing a similar method

697 as previously reported (Urbanek et al., 2014). Top10 E. coli expressing the tret gene from

698 Thermoproteus tenax (pBAD plasmid, AraC control) were streaked onto a Lysogeny broth (LB)

699 agar plate supplemented with $100 \mu \mathrm{g} / \mathrm{mL}$ ampicillin and incubated at $37^{\circ} \mathrm{C}$ for $24 \mathrm{~h}$. A single

700 colony was picked and used to inoculate $5 \mathrm{~mL}$ of LB liquid medium containing $100 \mu \mathrm{g} / \mathrm{mL}$

701 ampicillin. The starter culture was placed in a shaking incubator $(175 \mathrm{rpm})$ at $37{ }^{\circ} \mathrm{C}$ for $16 \mathrm{~h}$. The

702 starter culture was then transferred to a $1 \mathrm{~L}$ solution of sterilized Terrific broth (TB)

703 supplemented with $100 \mu \mathrm{g} / \mathrm{mL}$ ampicillin in a sterilized $2 \mathrm{~L}$ Fernbach culture flask. The flask

704 was shaken $(175 \mathrm{rpm})$ at $37^{\circ} \mathrm{C}$. When the absorbance at $600 \mathrm{~nm}$ reached between 0.6 and 0.9

705 (typically $4-5 \mathrm{~h}$ post inoculation), TreT expression was induced by adding $1 \mathrm{~mL}$ of $1 \mathrm{M}$

706 arabinose solution in sterile water ( $1 \mathrm{mM}$ final concentration). The flask was again shaken (175

$707 \mathrm{rpm}$ ) at $37^{\circ} \mathrm{C}$ for another $20 \mathrm{~h}$. The culture was then transferred to a polypropylene bottle and

708 pelleted for 15 minutes at $4,000 \mathrm{xg}$ at $4{ }^{\circ} \mathrm{C}$. The supernatant was discarded, and the pellet was

709 suspended in $45 \mathrm{~mL}$ of lysis buffer (50 mM NaH${ }_{2} \mathrm{PO}_{4}, 500 \mathrm{mM} \mathrm{NaCl}, 20 \mathrm{mM}$ imidazole, $\mathrm{pH}$ 7.4)

710 and run through a homogenizer 5 times utilizing ice to keep the solution cool. Once

711 homogenized, the lysate was clarified by centrifugation pelleting for 20 minutes at 21,000 x $\mathrm{g}$ at

$7124{ }^{\circ} \mathrm{C}$ and filtering through a $0.45 \mu \mathrm{m}$ Teflon syringe filter. To the clarified lysate (generally about

$71350 \mathrm{mg} / \mathrm{mL}$ protein content as measured with absorbance at $280 \mathrm{~nm}$ ) was then added $5 \mathrm{~mL}$ of pre-

714 washed (lysis buffer) Ni-NTA resin slurry (Qiagen). The suspension was mixed on an orbital

715 shaker for $60-90$ minutes at $4{ }^{\circ} \mathrm{C}$ and then transferred to a glass column (BIO-RAD

716 EconoColumn). Non-His-Tagged proteins were eluted with lysis buffer until the absorbance at

$717280 \mathrm{~nm}$ matched background levels utilizing 50-100 mL of lysis buffer. His-tagged TreT was

718 eluted with elution buffer $\left(50 \mathrm{mM} \mathrm{NaH}_{2} \mathrm{PO}_{4}, 500 \mathrm{mM} \mathrm{NaCl}, 250 \mathrm{mM}\right.$ imidazole, $\mathrm{pH}$ 7.4) in

719 multiple $2.5 \mathrm{~mL}$ increments, until protein elution was determined complete by absorbance at 280

$720 \mathrm{~nm}$. Buffer exchange to a storage/reaction buffer (50 mM Tris, $300 \mathrm{mM} \mathrm{NaCl}, \mathrm{pH} 8.0$ ) was

721 performed with a desalting column (PD-10, GE Healthcare) and the protein was transferred to a 
722

723

724

725

726

727

728

729

730

731

732

733

734

735

736

737

738

739

740

741

742

743

744

745

746

747

748

749

750

751

752

conical tube and diluted to $1 \mathrm{mg} / \mathrm{mL}$ as determined by absorbance at $280 \mathrm{~nm}$ for long-term storage. Storage of the enzyme at $4{ }^{\circ} \mathrm{C}$ and at this concentration yields active protein that does not have significant losses in activity even after 12 months of storage under these conditions.

Synthesis and Purification of 6-Azido-6-deoxy-trehalose (6-TreAz): To a $1.5 \mathrm{~mL}$ Eppendorf tube was added $200 \mu \mathrm{L}$ of a $100 \mathrm{mM}$ solution of 6-azido-6-deoxy-glucose (final concertation $20 \mathrm{mM}$ ), $100 \mu \mathrm{L}$ of a freshly-prepared $400 \mathrm{mM}$ solution of UDP-glucose (final concentration $40 \mathrm{mM}$ ), $100 \mu \mathrm{L}$ of a $200 \mathrm{mM}$ solution of $\mathrm{MgCl}_{2}$ (final concentration $20 \mathrm{mM}$ ), and $300 \mathrm{~mL}$ of reaction buffer (50 mM Tris, $300 \mathrm{mM} \mathrm{NaCl}$, pH 7.4). Then, $300 \mu \mathrm{L}$ of TreT solution in storage/reaction buffer was added (final concentration $300 \mu \mathrm{g} / \mathrm{mL}$ ) and the reaction vessel was closed and mixed gently by inverting the tube. The reaction was heated to $70{ }^{\circ} \mathrm{C}$ for $60-90$ minutes with shaking at $400 \mathrm{rpm}$ and then cooled on ice before further manipulation. The reaction contents were transferred to a pre-washed Amicon centrifugal filter with a nominal molecular weight limit (NWML) of $10 \mathrm{kDa}$. The filter was washed with DI water $(2 \times 1 \mathrm{~mL})$ to facilitate maximal recovery. The upper chamber was discarded and $1 \mathrm{~g}$ of prewashed mixed-bed ion-exchange resin (DOWEX) was added to the filtrate and the slurry was equilibrated for $60-90$ minutes. The suspension was filtered, and the resin was rinsed with $3-5 \mathrm{~mL}$ of DI water. Analysis by TLC (5:3:2 n-butanol: ethanol: DI water) and/or LC-MS equipped with a Supelco aminopropyl column [4.6 x $250 \mathrm{~mm}, 5 \mu \mathrm{m}$ ] (isocratic $80 \% \mathrm{ACN}$ in DI water, $0.5 \mathrm{~mL} / \mathrm{min}$ flowrate) indicated full and complete conversion of 6-azido-6-deoxy-glucose to 6-azido-6-deoxy-trehalose with high purity as determined by nuclear magnetic resonance (NMR), which matched previously reported spectra.

Synthesis and Direct utilization of 6-TreAz for labeling Mycobacterium marinum: To facilitate easier production and labeling of M. marinum with 6-TreAz, the reaction was performed as above but 6-TreAz was not isolated prior to labeling. Upon reaction completion, the reaction was cooled on ice to bring the vessel back to ambient temperature. The $10 \mathrm{mM}$ stock of 6-TreAz was then added to cultures of Mycobacterium marinum to a final concentration of $50 \mu \mathrm{M}$. 


\section{Periodate-hydroxylamine staining of mycobacterial surfaces}

754 Surface-exposed terminal oxidizable carbohydrates were labeled with hydroxylamine following

755 periodate oxidation. Lyophilized control or reconstituted M. marinum were washed twice with

756 PBS and resuspended in 0.1 M sodium acetate (Sigma), pH 5.5 containing $1 \mathrm{mM}$ sodium

757 periodate (Sigma). Following a 20 -min incubation at $4^{\circ} \mathrm{C}$ with gentle rotation, $0.1 \mathrm{mM}$ glycerol

758 was added to stop the reaction. Cultures were washed three times with PBS and then subjected to

759 single cell preparation. Following single cell preparation, pellets were transferred to a 96-well

760 plate and then incubated with PBS containing $1 \mathrm{mM}$ Alexa-647 hydroxylamine (Thermo-Fisher).

761 Following a $2 \mathrm{~h}$ incubation at $23{ }^{\circ} \mathrm{C}$, the cultures were washed 5 times with PBS and twice with

762 prep media.

\section{Copper-free click chemistry of M. marinum}

765 Following reconstitution or metabolic labeling, bacteria were treated for single cell preparation.

766 Bacteria were then transferred to 96-well v-bottom dishes and were washed twice with PBS

767 using centrifugation at 3000xg for $3 \mathrm{~min}$ between washing. Bacteria were then stained with either

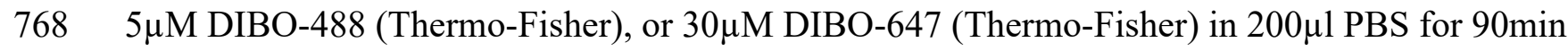

769 at $23{ }^{\circ} \mathrm{C}$ protected from light. Bacteria were then washed 5 times in PBS followed by 2 washes in

770 prep media. Bacteria were then aliquoted and stored at -20C for future use. Staining efficiency

771 was evaluated by flow cytometry on a BD-Accuri C6 Plus and analysis was performed using the

772 FlowJo software package. Staining was also evaluated by microscopy with a 60x oil-immersion

773 Plan Apo 1.4 NA objective on the Nikon A1R confocal microscope.

\section{MYD88 morpholino and liposome injections}

776 To generate MYD88 knockdown zebrafish larvae, the MYD88 morpholino

777 5'GTTAAACACTGACCCTGTGGATCAT3' (Bates et al., 2007) was diluted to 2mM in $0.5 \mathrm{x}$

778 tango buffer (Thermo Scientific), containing 2\% phenol red sodium salt solution (Sigma). $1 \mathrm{nl}$ of

779 the morpholino mixture was injected into the 1-4 cell stage of the developing embryo. Lipo-PBS

780 and lipo-clodronate (http://clodronateliposomes.org) were diluted 1:10 in PBS and injected into

781 2-dpf-old larvae in $\sim 10 \mathrm{nl}$ via the caudal vein. 


\section{Confocal microscopy and image-based quantification of infection}

785 Larvae were embedded in 1.5\% low melting point agarose (Thermo-Fisher) and a series of $\mathrm{z}$

786 stack images with a $2 \mu \mathrm{m}$ step size was generated through the infected HBV. For infected THP-1

787 and A549 cells, a series of z stack images with a $1 \mu \mathrm{m}$ step size was generated. Images were

788 captured using the galvo scanner (laser scanner) of the Nikon A1R confocal microscope with a

789 20x Plan Apo 0.75 NA objective. Higher resolution images were generated using a 40x water-

790 immersion Apo 1.15 NA objective. Bacterial burdens were determined by using the 3D surface-

791 rendering feature of Imaris (Bitplane Scientific Software). Spread lipid images were generated

792 by subtracting the bacterial surface from the lipid channel. 3D surface-rendering was then done

793 in Imaris on both the total lipid and spread lipid images to generate a percent spread value.

\section{Macrophage and Monocyte hindbrain recruitment assay}

796 For the macrophage recruitment (Figure 1G): 2 dpf zebrafish were infected in the HBV with $M$.

797 marinum at the dose reported in the figure legends. At $3 \mathrm{~h}$ post infection, the number of total

798 myeloid cells in the HBV was quantified using differential interference contrast microscopy

799 using a 20x Plan Fluor 0.75 NA objective on Nikon's Ti eclipse inverted microscope. For

800 quantification of monocytes (Figure 5A and B): 2 dpf zebrafish were injected in the caudal vein

801 with $200 \mu \mathrm{g} / \mathrm{ml}$ of the nuclear stain Hoechst 33342 (Thermo-Fisher) 2 hours prior to HBV

802 infection. Hoechst is unable to cross the blood-brain barrier and therefore will label circulating

803 monocytes but will not label brain resident macrophages (Cambier et al., 2017). At 3hpi blue-

804 fluorescent cells in the hindbrain was quantified similar to above macrophage recruitment assay.

\section{Co-infection Experiments}

807 Around 40-50 tdTomato expressing wildtype M. mairnum were co-infected with an equal

808 number of wasabi expressing M. marinum into the HBV. At 3 dpi the bacterial volume of the

809 wildtype tdTomato expressing M. marinum was quantified as described above (Confocal

810 microscopy and image-based quantification of infection).

\section{Infectivity Assay}

8133 days post fertilization larvae were infected via the hindbrain ventricle with an average of 0.8

814 bacteria per injection. Fish harboring 1-3 bacteria were identified at $5 \mathrm{~h}$ post infection by 
815 confocal microscopy. These infected fish were then evaluated at 3 dpi and were scored as

816 infected or uninfected, based on the presence or absence of fluorescent bacteria.

\section{Fluorescence recovery after photobleaching (FRAP) experiments}

819 FRAP experiments were performed using the galvo scanner (laser scanner) of the Nikon A1R

820 confocal microscope with a 60x oil-immersion Plan Apo 1.4 NA objective. Photobleaching was

821 performed with the $405 \mathrm{~nm}$ laser for $200 \mathrm{~ms}$ on a region of interest (ROI) encompassing $\sim 1 \mu \mathrm{m}$

822 from one pole of a single bacteria. A series of images was taken every second over the course of

82331 seconds, one prior to bleaching. Labeled cells were mounted on a slide and coverslip in

$824 \quad 0.75 \%$ low melting agarose. NIS Elements software (Nikon) was used to analyze the FRAP data

825 to extract the fluorescence recovery kinetics. Briefly, the first image before photobleaching was

826 used to generate an ROI for the entire cell and a second ROI was generated in the photobleached

827 area. Total fluorescence intensities in both the whole cell area and the bleached area were

828 extracted and normalized to correct for photobleaching of the dyes due to acquisition. The

829 normalized fluorescence intensities of the bleached area were then fitted to a non-linear

830 regression with a one-phase association, with the plateau values from each sample plotted to

831 represent the mobile fraction.

\section{Alkyne-cholesterol labeling of $M$. marinum}

834 Wildtype or $\Delta m m p L 7$ M. marinum expressing wasabi fluorescent protein were grown in $7 \mathrm{H} 9$

835 medium supplemented with $10 \%$ OADC, $0.2 \%$ glycerol with or without $0.005 \%$ alkyne-

836 cholesterol for $48 \mathrm{~h}$. Bacteria were then washed 3x with PBS prior to the copper-click reaction

837 with AlexaFluor-647 Azide. For copper click: 400 $\mu$ M BTTP (Click Chemistry Tools) and

$838200 \mu \mathrm{M}$ copper sulfate (Sigma) were dissolved in PBS and allowed to complex for 20 minutes.

$83930 \mu \mathrm{M}$ AlexaFluor-647 Azide (Thermo-Fisher) and 1.2mM sodium ascorbate (Sigma) were then

840 added to the solution. Bacterial pellets in 96-well v-bottom plates were resuspended in $50 \mu 1$ of

841 the solution and were incubated at $23{ }^{\circ} \mathrm{C}$ protected from light for 45 minutes. Bacteria were then

842 washed 5x in PBS prior to imaging on a Nikon A1R confocal microscope with a 60x oil-

843 immersion Plan Apo 1.4 NA objective. Nikon elements software was used to determine

844 fluorescent intensities of wasabi and cholesterol signals calculated from line profiles drawn

845 perpendicular to bacterial membranes at least $0.5 \mu \mathrm{m}$ from either pole. 
Cholesterol depletion and infection of A549 epithelial cells A549 cells were seeded at 50,000 cells per 8-well Nunc Lab-Tek II chambered coverglass or at 100,000 cells per well in a 24 well plate. Cells were incubated at $37^{\circ} \mathrm{C}$ for $48 \mathrm{~h}$. Cells were washed 1x in PBS followed by treatment with $10 \mathrm{mM}$ methyl- $\beta$ cyclodextrin (Sigma), $1 \mathrm{mM}$ water-soluble cholesterol (Sigma), or a combination of $10 \mathrm{mM}$ methyl- $\beta$ cyclodextrin and $1 \mathrm{mM}$ water-soluble cholesterol in serum free DMEM media. Cells were treated for 1 hour at $33{ }^{\circ} \mathrm{C}$ followed by 3 washes with PBS. Cells plated on chambered coverglass were infected with azidoDIM labeled M. marinum at an MOI of 5 for $24 \mathrm{~h}$ at $33^{\circ} \mathrm{C}$ followed by imaging on a Nikon A1R confocal microscope with a 20x Plan Apo 0.75 NA objective. $2 \mu \mathrm{m}$ z-stacks were generated through the infected cells. Azido-DIM spreading was calculated similar to above (Section: Confocal microscopy and image-based quantification of infection). Cells plated on 24-well plates were rescued in DMEM $+10 \%$ FBS for $3 \mathrm{~h}$ at $33{ }^{\circ} \mathrm{C}$. Cells were then harvested for quantification of cholesterol levels.

\section{Atorvastatin treatment of zebrafish larvae}

862 At $48 \mathrm{~h}$ post fertilization, $0.5 \mu \mathrm{M}$ atorvastatin (Sigma), or $10 \mu \mathrm{M}$ water-soluble cholesterol

863 (Sigma), or both were added to zebrafish water containing 1\% DMSO. Control fish were

864 incubated in water with 1\% DMSO only. Zebrafish were incubated for $24 \mathrm{~h}$ prior to infection or

865 to cholesterol quantification. Drugs were replenished every $24 \mathrm{~h}$ until experiment endpoint.

Quantification of cholesterol in zebrafish and A549 epithelial cells

868 Cholesterol was quantified using the Total Cholesterol and Cholesterol Ester

869 Colorimetric/Fluorometric Assay Kit (BioVision). For zebrafish, 8 larvae were euthanized,

870 transferred to a $1.5 \mathrm{ml}$ Eppendorf tube and excess water was removed. A solution of

871 chloroform:isopropanol:NP-40 (7:11:0.1) was added and the sample was sonicated in a water

872 bath for 1 hour. Samples were then centrifuged at 16,000xg for 10min and supernatants were

873 transferred to a fresh tube and were allowed to dry in a $60^{\circ} \mathrm{C}$ water in a chemical fume hood. For

874 A549 epithelial cells, chloroform:isopropanol:NP-40 (7:11:0.1) was added directly to cells in a

87524 well plate. Cells were scrapped and solution was transferred to a $1.5 \mathrm{ml}$ Eppendorf tube and 
877

878

879

880

\section{1}

882

883

884

885

886

887

were allowed to dry in a $60^{\circ} \mathrm{C}$ water in a chemical fume hood. Dried lipids were then subjected to manufacturer's protocol and total cholesterol concentrations were determined by fluorescence on a SpectraMax i3x plate reader (Molecular Devices).

\section{Statistics}

Statistical analyses were performed using Prism 8.4.3 (GraphPad): When appropriate D'Agostino-Pearson normality test was done to determine if all of the groups in a particular data set were of a gaussian distribution which then guided the subsequent statistical test performed (Supplemental Table 1). Where the $n$ value is given and not represented graphically in the figure, $n$ represents the number of zebrafish used for each experimental group (Figure $7 \mathrm{H}$ and I).

\section{REFERENCES}

Anderson, R.J. (1929). The chemistry of the lipoids of tubercle bacilli iv. concerning the so called tubercle bacilli wax. analysis of the purified wax. J. Biol. Chem. 83, 505-522.

Astarie-Dequeker, C., Le Guyader, L., Malaga, W., Seaphanh, F.-K., Chalut, C., Lopez, A., and Guilhot, C. (2009). Phthiocerol Dimycocerosates of M. tuberculosis Participate in Macrophage Invasion by Inducing Changes in the Organization of Plasma Membrane Lipids. PLoS Pathog 5, e1000289-16.

Augenstreich, J., Arbues, A., Siméone, R., Haanappel, E., Wegener, A., Sayes, F., Le Chevalier, F., Chalut, C., Malaga, W., Guilhot, C., et al. (2017). ESX-1 and phthiocerol dimycocerosates of Mycobacterium tuberculosis act in concert to cause phagosomal rupture and host cell apoptosis. Cellular Microbiology 19.

Augenstreich, J., Haanappel, E., Ferré, G., Czaplicki, G., Jolibois, F., Destainville, N., Guilhot, C., Milon, A., Astarie-Dequeker, C., and Chavent, M. (2019). The conical shape of DIM lipids promotes Mycobacterium tuberculosis infection of macrophages. Proceedings of the National Academy of Sciences 3, 201910368.

Barczak, A.K., Avraham, R., Singh, S., Luo, S.S., Zhang, W.R., Bray, M.-A., Hinman, A.E., Thompson, M., Nietupski, R.M., Golas, A., et al. (2017). Systematic, multiparametric analysis of Mycobacterium tuberculosis intracellular infection offers insight into coordinated virulence. PLoS Pathog 13, e1006363-27.

Bates, J.H., Potts, W.E., and Lewis, M. (1965). Epidemiology of Primary Tuberculosis in an Industrial School. N. Engl. J. Med. 272, 714-717.

Bates, J.M., Akerlund, J., Mittge, E., and Guillemin, K. (2007). Intestinal alkaline phosphatase detoxifies lipopolysaccharide and prevents inflammation in zebrafish in response to the gut microbiota. Cell Host \& Microbe 2, 371-382. 
912 Beatty, W.L., Rhoades, E.R., Ullrich, H.J., Chatterjee, D., Heuser, J.E., and Russell, D.G. (2000).

913 Trafficking and release of mycobacterial lipids from infected macrophages. Traffic 1, 235-247.

914 Bernut, A., Herrmann, J.-L., Kissa, K., Dubremetz, J.-F., Gaillard, J.-L., Lutfalla, G., and

915 Kremer, L. (2014). Mycobacterium abscessus cording prevents phagocytosis and promotes

916 abscess formation. Proceedings of the National Academy of Sciences 111, E943-E952.

917 Brzostek, A., Pawelczyk, J., Rumijowska-Galewicz, A., Dziadek, B., and Dziadek, J. (2009).

918 Mycobacterium tuberculosis Is Able To Accumulate and Utilize Cholesterol. Journal of

919 Bacteriology 191, 6584-6591.

920 Budin, I., de Rond, T., Chen, Y., Chan, L.J.G., Petzold, C.J., and Keasling, J.D. (2018). Viscous

921 control of cellular respiration by membrane lipid composition. Science 362, 1186-1189.

922 Camacho, L.R., Constant, P., Raynaud, C., Lanéelle, M.-A., Triccas, J.A., Gicquel, B., Daffé,

923 M., and Guilhot, C. (2001). Analysis of the Phthiocerol Dimycocerosate Locus of

924 Mycobacterium tuberculosis. J. Biol. Chem. 276, 19845-19854.

925 Cambier, C.J., Falkow, S., and Ramakrishnan, L. (2014a). Host evasion and exploitation

926 schemes of Mycobacterium tuberculosis. Cell 159, 1497-1509.

927 Cambier, C.J., O’Leary, S.M., O’Sullivan, M.P., Keane, J., and Ramakrishnan, L. (2017).

928 Phenolic Glycolipid Facilitates Mycobacterial Escape from Microbicidal Tissue-Resident

929 Macrophages. Immunity 47, 552-565.e554.

930 Cambier, C.J., Takaki, K.K., Larson, R.P., Hernandez, R.E., Tobin, D.M., Urdahl, K.B., Cosma, 931 C.L., and Ramakrishnan, L. (2014b). Mycobacteria manipulate macrophage recruitment through

932 coordinated use of membrane lipids. Nature 505, 218-222.

933 Cohen, S.B., Gern, B.H., Delahaye, J.L., Adams, K.N., Plumlee, C.R., Winkler, J.K., Sherman,

934 D.R., Gerner, M.Y., and Urdahl, K.B. (2018). Alveolar Macrophages Provide an Early

935 Mycobacterium tuberculosis Niche and Initiate Dissemination. Cell Host \& Microbe 24, 439-

936 446.e4.

937 Comas, I., Coscolla, M., Luo, T., Borrell, S., Holt, K.E., Kato-Maeda, M., Parkhill, J., Malla, B., 938 Berg, S., Thwaites, G., et al. (2013). Out-of-Africa migration and Neolithic coexpansion of 939 Mycobacterium tuberculosis with modern humans. Nat. Genet. 45, 1176-1182.

940 Cox, J.S., Chen, B., McNeil, M., and Jacobs, W.R. (1999). Complex lipid determines tissue941 specific replication of Mycobacterium tuberculosis in mice. Nature 402, 79-83.

942 Davis, J.M., and Ramakrishnan, L. (2009). The role of the granuloma in expansion and 943 dissemination of early tuberculous infection. Cell 136, 37-49.

944 Dutta, N.K., Bruiners, N., Pinn, M.L., Zimmerman, M.D., Prideaux, B., Dartois, V., Gennaro, 945 M.L., and Karakousis, P.C. (2016). Statin adjunctive therapy shortens the duration of TB 946 treatment in mice. J. Antimicrob. Chemother. 71, 1570-1577. 
947 Falkow, S. (1988). Molecular Koch's postulates applied to microbial pathogenicity. Rev. Infect.

948 Dis. 10 Suppl 2, S274-S276.

949 Falkow, S. (2004). Molecular Koch's postulates applied to bacterial pathogenicity--a personal

950 recollection 15 years later. Nat. Rev. Microbiol. 2, 67-72.

951 Fessler, M.B. (2017). A New Frontier in Immunometabolism. Cholesterol in Lung Health and

952 Disease. Ann Am Thorac Soc 14, S399-S405.

953 Gatfield, J., and Pieters, J. (2000). Essential role for cholesterol in entry of mycobacteria into 954 macrophages. Science 288, 1647-1650.

955 Howell, J.I., Ahkong, Q.F., Cramp, F.C., Fisher, D., Tampion, W., and Lucy, J.A. (1972).

956 Membrane fluidity and membrane fusion. Biochem. J. 130, 44P-44P.

957 Huebinger, J., Spindler, J., Holl, K.J., and Koos, B.X.R. (2018). Quantification of protein 958 mobility and associated reshuffling of cytoplasm during chemical fixation. Scientific Reports 195911.

960 Indrigo, J. (2003). Cord factor trehalose 6,6'-dimycolate (TDM) mediates trafficking events 961 during mycobacterial infection of murine macrophages. Microbiology 149, 2049-2059.

962 Jackson, M. (2014). The mycobacterial cell envelope-lipids. Cold Spring Harb Perspect Med 4.

963 Jung, M.E., and Lyster, M.A. (1977). Quantitative dealkylation of alkyl ethers via treatment with 964 trimethylsilyl iodide. A new method for ether hydrolysis. J. Org. Chem. 42, 3761-3764.

965 Kamariza, M., Shieh, P., Ealand, C.S., Peters, J.S., Chu, B., Rodriguez-Rivera, F.P., Babu Sait, 966 M.R., Treuren, W.V., Martinson, N., Kalscheuer, R., et al. (2018). Rapid detection of

967 Mycobacterium tuberculosis in sputum with a solvatochromic trehalose probe. Sci Transl Med

96810 , eaam6310.

969 Karakousis, P.C., Chaisson, R.E., Martinson, N. (2019) StAT-TB (Statin Adjunctive Therapy for 970 TB): A Phase 2b Dose-finding Study of Pravastatin in Adults with Tuberculosis. National 971 Institute of Allergy and Infectious Diseases. https://clinicaltrials.gov/ct2/show/NCT03882177

972 Kim, M.-C., Yun, S.-C., Lee, S.-O., Choi, S.-H., Kim, Y.S., Woo, J.H., and Kim, S.-H. (2019).

973 Association between Tuberculosis, Statin Use, and Diabetes: A Propensity Score-Matched

974 Analysis. The American Journal of Tropical Medicine and Hygiene 101, 350-356.

975 Kondo, E., and Kanai, K. (1976). A suggested role of a host-parasite lipid complex in 976 mycobacterial infection. Jpn. J. Med. Sci. Biol. 29, 199-210.

977 Lai, C.-C., Lee, M.-T.G., Lee, S.-H., Hsu, W.-T., Chang, S.-S., Chen, S.-C., and Lee, C.-C.

978 (2016a). Statin treatment is associated with a decreased risk of active tuberculosis: an analysis of 979 a nationally representative cohort. Thorax 71, 646-651. 
980 Lai, C.-C., Lee, M.-T.G., Lee, S.-H., Hsu, W.-T., Chang, S.-S., Chen, S.-C., and Lee, C.-C.

981 (2016b). Statin treatment is associated with a decreased risk of active tuberculosis: an analysis of

982 a nationally representative cohort. Thorax 71, 646-651.

983 Lerner, T.R., Queval, C.J., Fearns, A., Repnik, U., Griffiths, G., and Gutierrez, M.G. (2017).

984 Phthiocerol dimycocerosates promote access to the cytosol and intracellular burden of

985 Mycobacterium tuberculosis in lymphatic endothelial cells. 1-13.

986 Los, D.A., and Murata, N. (2004). Membrane fluidity and its roles in the perception of

987 environmental signals. Biochimica Et Biophysica Acta (BBA) - Biomembranes 1666, 142-157.

988 Maerz, L.D., Burkhalter, M.D., Schilpp, C., Wittekindt, O.H., Frick, M., and Philipp, M. (2019).

989 Pharmacological cholesterol depletion disturbs ciliogenesis and ciliary function in developing

990 zebrafish. Communications Biology 1-13.

991 Martens, G.W., Arikan, M.C., Lee, J., Ren, F., Vallerskog, T., and Kornfeld, H. (2008).

992 Hypercholesterolemia Impairs Immunity to Tuberculosis. Infection and Immunity 76, 3464-

9933472.

994 Medzhitov, R. (2007). Recognition of microorganisms and activation of the immune response.

995 Nature 449, 819-826.

996 Moliva, J.I., Hossfeld, A.P., Sidiki, S., Canan, C.H., Dwivedi, V., Beamer, G., Turner, J., and

997 Torrelles, J.B. (2019). Selective delipidation of Mycobacterium bovis BCG enables direct

998 pulmonary vaccination and enhances protection against Mycobacterium tuberculosis. Mucosal

999 Immunology 12, 805-815.

1000 Murry, J.P., Pandey, A.K., Sassetti, C.M., and Rubin, E.J. (2009). Phthiocerol dimycocerosate

1001 transport is required for resisting interferon-gamma-independent immunity. J Infect Dis 200,

$1002 \quad 774-782$.

1003 Nishijima, K., Yoneda, M., Hirai, T., Takakuwa, K., and Enomoto, T. (2019). Biology of the

1004 vernix caseosa: A review. J. Obstet. Gynaecol. Res. 45, 2145-2149.

1005 Onwueme, K.C., Vos, C.J., Zurita, J., Ferreras, J.A., and Quadri, L.E.N. (2005). The

1006 dimycocerosate ester polyketide virulence factors of mycobacteria. Progress in Lipid Research

1007 44, 259-302.

1008 Osman, M.M., Pagán, A.J., Shanahan, J.K., and Ramakrishnan, L. (2020). Mycobacterium 1009 marinumphthiocerol dimycocerosates enhance macrophage phagosomal permeabilization and 1010 membrane damage. bioRxiv 1-20.

1011 Pandey, A.K., and Sassetti, C.M. (2008). Mycobacterial persistence requires the utilization of

1012 host cholesterol. Proceedings of the National Academy of Sciences 105, 4376-4380.

1013 Poger, D., Caron, B., and Mark, A.E. (2014). Effect of Methyl-Branched Fatty Acids on the 1014 Structure of Lipid Bilayers. J. Phys. Chem. B 118, 13838-13848. 
1015 Quigley, J., Hughitt, V.K., Velikovsky, C.A., Mariuzza, R.A., El-Sayed, N.M., and Briken, V. 1016 (2017). The Cell Wall Lipid PDIM Contributes to Phagosomal Escape and Host Cell Exit of 1017 Mycobacterium tuberculosis. mBio 8, e00148-17-12.

1018 Ramakrishnan, L. (2012). Revisiting the role of the granuloma in tuberculosis. Nat Rev Immunol $1019 \quad 12,352-366$.

1020 Ramakrishnan, L. (2020). Mycobacterium tuberculosis pathogenicity viewed through the lens of 1021 molecular Koch’s postulates. Curr. Opin. Microbiol. 54, 103-110.

1022 Ran-Ressler, R.R., Khailova, L., Arganbright, K.M., Adkins-Rieck, C.K., Jouni, Z.E., Koren, O., 1023 Ley, R.E., Brenna, J.T., and Dvorak, B. (2011). Branched Chain Fatty Acids Reduce the 1024 Incidence of Necrotizing Enterocolitis and Alter Gastrointestinal Microbial Ecology in a 1025 Neonatal Rat Model. PLoS ONE 6, e29032-10.

1026 Reuschl, A.-K., Edwards, M.R., Parker, R., Connell, D.W., Hoang, L., Halliday, A., Jarvis, H., 1027 Siddiqui, N., Wright, C., Bremang, S., et al. (2017). Innate activation of human primary 1028 epithelial cells broadens the host response to Mycobacterium tuberculosis in the airways. PLoS 1029 Pathog 13, e1006577-26.

1030 Rodriguez-Rivera, F.P., Zhou, X., Theriot, J.A., and Bertozzi, C.R. (2017). Visualization of mycobacterial membrane dynamics in live cells. J. Am. Chem. Soc. 139, 3488-3495.

1032 Rousseau, C., Winter, N., Pivert, E., Bordat, Y., Neyrolles, O., Avé, P., Huerre, M., Gicquel, B., 1033 and Jackson, M. (2004). Production of phthiocerol dimycocerosates protects Mycobacterium 1034 tuberculosis from the cidal activity of reactive nitrogen intermediates produced by macrophages 1035 and modulates the early immune response to infection. Cellular Microbiology 6, 277-287.

1036 Ruysschaert, J.-M., and Lonez, C. (2015). Role of lipid microdomains in TLR-mediated 1037 signalling. BBA - Biomembranes 1848, 1860-1867.

1038 Siegrist, M.S., Swarts, B.M., Fox, D.M., Lim, S.A., and Bertozzi, C.R. (2015). Illumination of 1039 growth, division and secretion by metabolic labeling of the bacterial cell surface. FEMS

1041 Silva, C.L., Ekizlerian, S.M., and Fazioli, R.A. (1985). Role of cord factor in the modulation of 1042 infection caused by mycobacteria. Am. J. Pathol. 118, 238-247.

1043 Siméone, R., Constant, P., Malaga, W., Guilhot, C., Daffé, M., and Chalut, C. (2007). Molecular 1044 dissection of the biosynthetic relationship between phthiocerol and phthiodiolone 1045 dimycocerosates and their critical role in the virulence and permeability of Mycobacterium 1046 tuberculosis. FEBS Journal 274, 1957-1969.

1047 Sletten, E.M., and Bertozzi, C.R. (2009). Bioorthogonal chemistry: fishing for selectivity in a sea 1048 of functionality. Angew. Chem. Int. Ed. Engl. 48, 6974-6998. 
Soh, A.Z., Chee, C.B., Wang, Y.-T., Yuan, J.-M., and Koh, W.-P. (2016). Dietary Cholesterol Increases the Risk whereas PUFAs Reduce the Risk of Active Tuberculosis in Singapore Chinese. The Journal of Nutrition 146, 1093-1100. apical lipid raft receptor complex to signal infection in airway epithelial cells. J. Clin. Invest. $113,1482-1489$.

1055 Srivastava, S., Ernst, J.D., and Desvignes, L. (2014). Beyond macrophages: the diversity of 1056 mononuclear cells in tuberculosis. Immunol. Rev. 262, 179-192.

1057 Swarts, B.M., Holsclaw, C.M., Jewett, J.C., Alber, M., Fox, D.M., Siegrist, M.S., Leary, J.A., 1058 Kalscheuer, R., and Bertozzi, C.R. (2012). Probing the mycobacterial trehalome with 1059 bioorthogonal chemistry. J. Am. Chem. Soc. 134, 16123-16126.

1060 Takaki, K., Davis, J.M., Winglee, K., and Ramakrishnan, L. (2013). Evaluation of the 1061 pathogenesis and treatment of Mycobacterium marinum infection in zebrafish. Nat Protoc 8 , 1062 1114-1124.

1063 Tall, A.R., and Yvan-Charvet, L. (2015). Cholesterol, inflammation and innate immunity. Nature 1064 Publishing Group 1-13.

1065 Urbanek, B.L., Wing, D.C., Haislop, K.S., Hamel, C.J., Kalscheuer, R., Woodruff, P.J., and 1066 Swarts, B.M. (2014). Chemoenzymatic Synthesis of Trehalose Analogues: Rapid Access to 1067 Chemical Probes for Investigating Mycobacteria. Chembiochem 15, 2066-2070.

1068 Urdahl, K.B. (2014). Understanding and overcoming the barriers to T cell-mediated immunity 1069 against tuberculosis. Seminars in Immunology 26, 578-587.

1070 van der Wel, N., Hava, D., Houben, D., Fluitsma, D., van Zon, M., Pierson, J., Brenner, M., and Peters, P.J. (2007). M. tuberculosis and M. leprae translocate from the phagolysosome to the 1072 cytosol in myeloid cells. Cell 129, 1287-1298.

1073 Volkman, H.E., Pozos, T.C., Zheng, J., Davis, J.M., Rawls, J.F., and Ramakrishnan, L. (2010). 1074 Tuberculous Granuloma Induction via Interaction of a Bacterial Secreted Protein with Host 1075 Epithelium. Science 327, 466-469.

1076 Walton, E.M., Cronan, M.R., Beerman, R.W., and Tobin, D.M. (2015). The Macrophage1077 Specific Promoter mfap4 Allows Live, Long-Term Analysis of Macrophage Behavior during 1078 Mycobacterial Infection in Zebrafish. PLoS ONE 10, e0138949.

1079 Wells, W.F., Ratcliffe, H.L., and Grumb, C. (1948). On the mechanics of droplet nuclei 1080 infection; quantitative experimental air-borne tuberculosis in rabbits. Am J Hyg 47, 11-28. 


\section{Supplemental Figures, Movie, and Table}

A

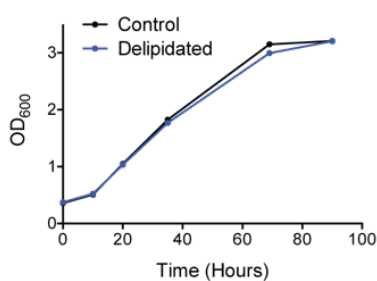

D

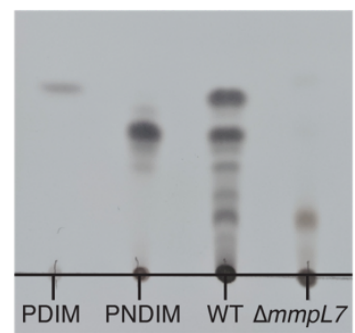

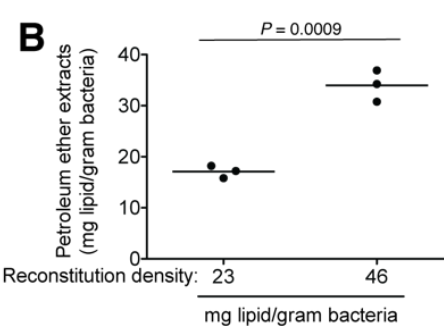

E

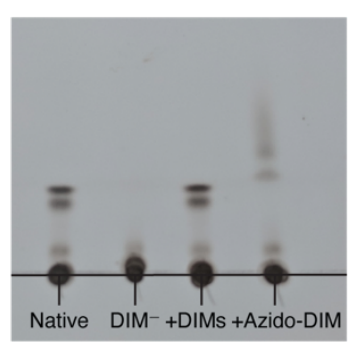

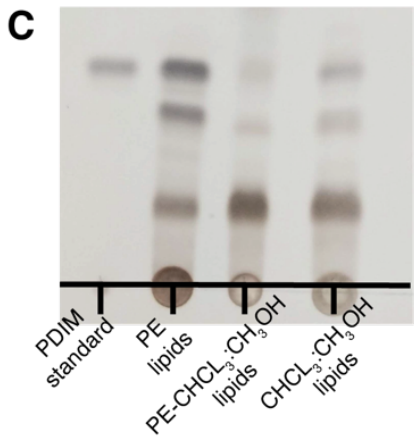

Supplemental Figure 1. Optimization of petroleum ether extraction and reconstitution. (A) Mean $\mathrm{OD}_{600}$ values of control or delipidated $M$. marinum recovered in complete growth medium. (B) Mean $\mathrm{mg}$ of lipid extracted per gram of dry bacteria following reconstitution with designated lipid densities. Two-tailed, unpaired t test. (C) Thin-layer chromatography (TLC) showing PDIM's complete removal following petroleum ether extraction. PDIM standard, petroleum ether extract (PE lipids), chloroform:methanol extract of the bacterial pellet previously extracted with petroleum ether (PE-CHCL3:CH3OH lipids), and chloroform:methanol extract of a fresh bacterial pellet (CHCL3:CH3OH lipids). TLC was ran twice in 98:2 petroleum ether:ethyl acetate. (D) TLC of PDIM standard, PNDIM standard, and petroleum ether extracts of wildtype (WT) and $\triangle m m p L 7$ M. marinum. TLC was ran twice in 98:2 petroleum ether:ethyl acetate. (E) TLC of Native, DIM depleted (DIM-), DIM- plus native DIMs (+DIMs), or DIM- plus azido-DIM (+Azido-DIM) lipids prior to reconstitution onto delipidated bacteria. TLC was ran once in 98:2 petroleum ether:ethyl acetate. (A)-(E) representative of three separate experiments. 
bioRxiv preprint doi: https://doi.org/10.1101/845081; this version posted June 30, 2020. The copyright holder for this preprint (which was not certified by peer review) is the author/funder, who has granted bioRxiv a license to display the preprint in perpetuity. It is made available under aCC-BY-NC-ND 4.0 International license.

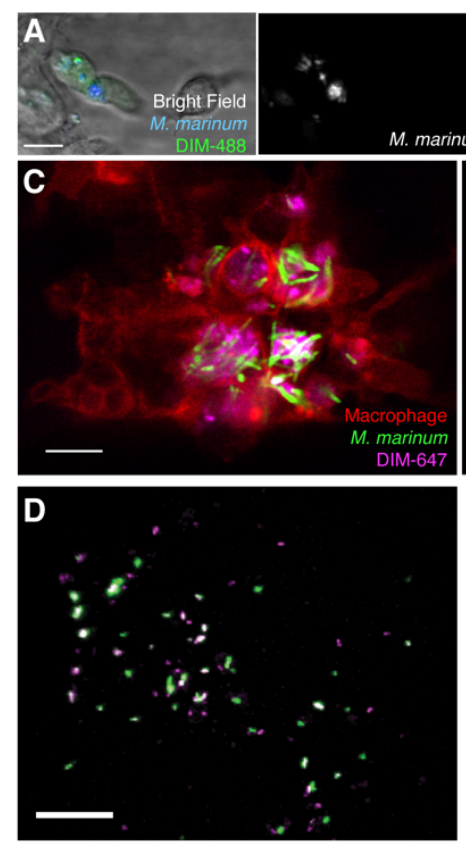

Bacteria Azido-DIM
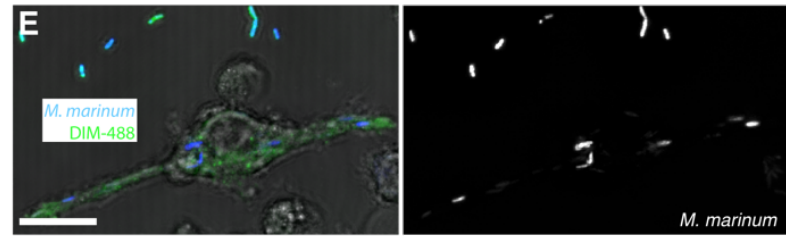

Total azido-DIM

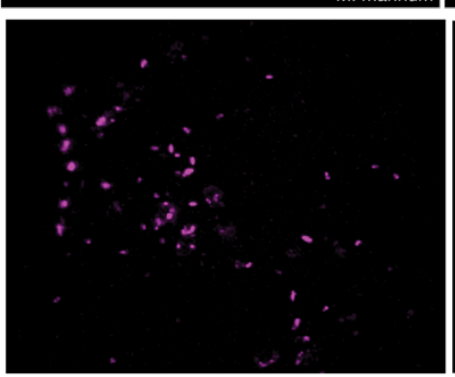

marinum
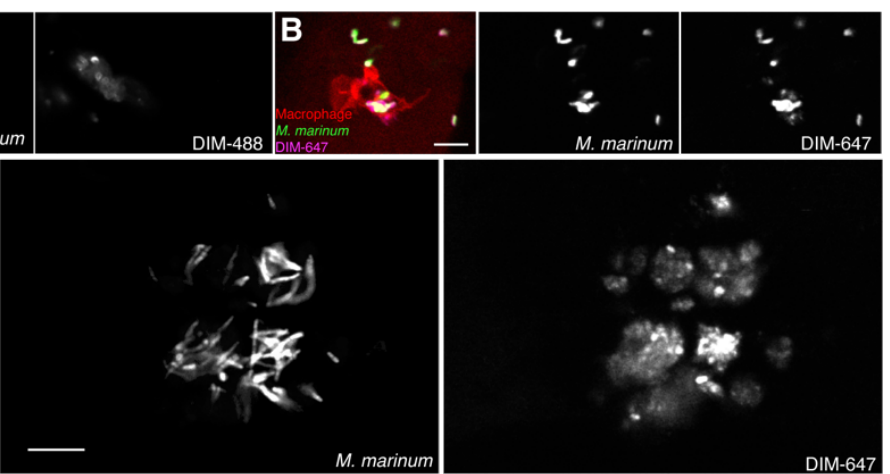

Supplemental Figure 2. Further characterization of PDIM spread. (A) Image of $M$. marinum expressing a cytosolic blue fluorescent protein reconstituted with DIBO-488 (green) labeled azido-DIM at 3hpi of $\sim 100 \mathrm{M}$. marinum in the HBV of wildtype fish. Scale bar $=10 \mu \mathrm{m}$. Images of $M$. marinum expresisng a cytosolic wasabi flourescent protein reconstituted with DIBO-647 labelled azido-DIM (DIM-647) at (B) 3 hours post infection and (C) 3 days post infection of $\sim 100 \mathrm{M}$. marinum in the HBV of transgenic fish whose macrophages express the red flourescent protein tdTomato. Scale bar $=10 \mu \mathrm{m}$. (D) Example of calculating percent spread: A surface rendering of the cytosolic expressing protein of the flourescent bacteria (green) is subtracted from the total azido-DIM signal (magenta) to give the spread azido-DIM signal. The volume of the spread azido-DIM signal is then divided by the volume of the total azido-DIM signal to calculate percent spread. Scale bar $=50 \mu \mathrm{m}$. (E) Image of $M$. marinum expresisng a blue fluorescent protein reconstituted with DIM-488 $24 \mathrm{hpi}$ of THP-1 macrophages, MOI $=5$, and scale bar $=10 \mu \mathrm{m}$. 


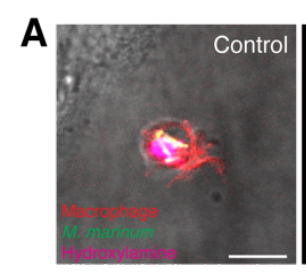

B

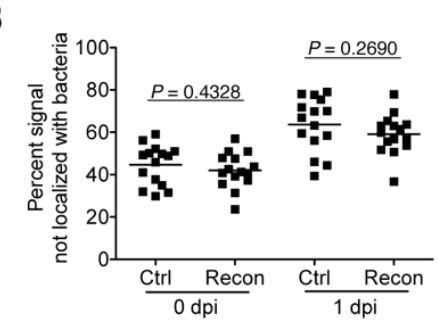

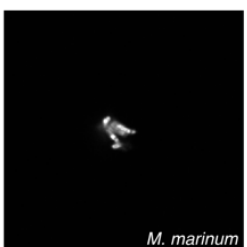

C
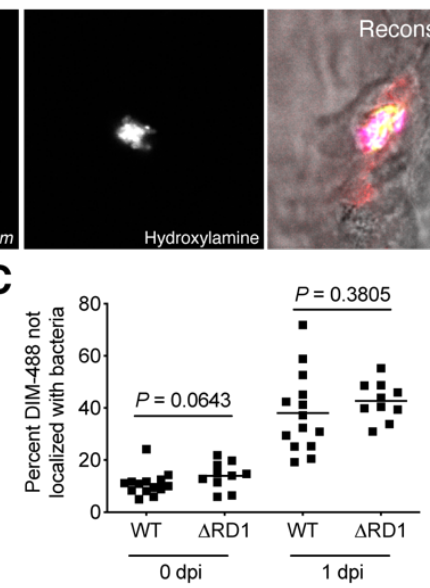

西
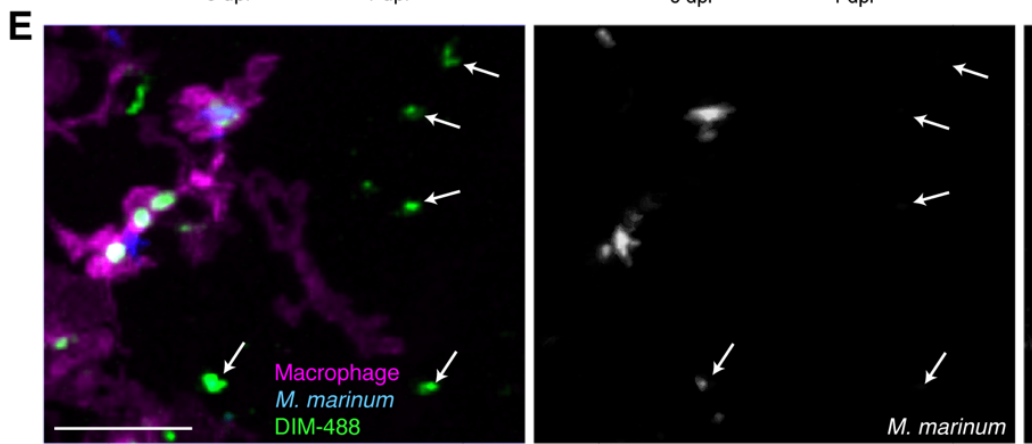

M. marinum

D
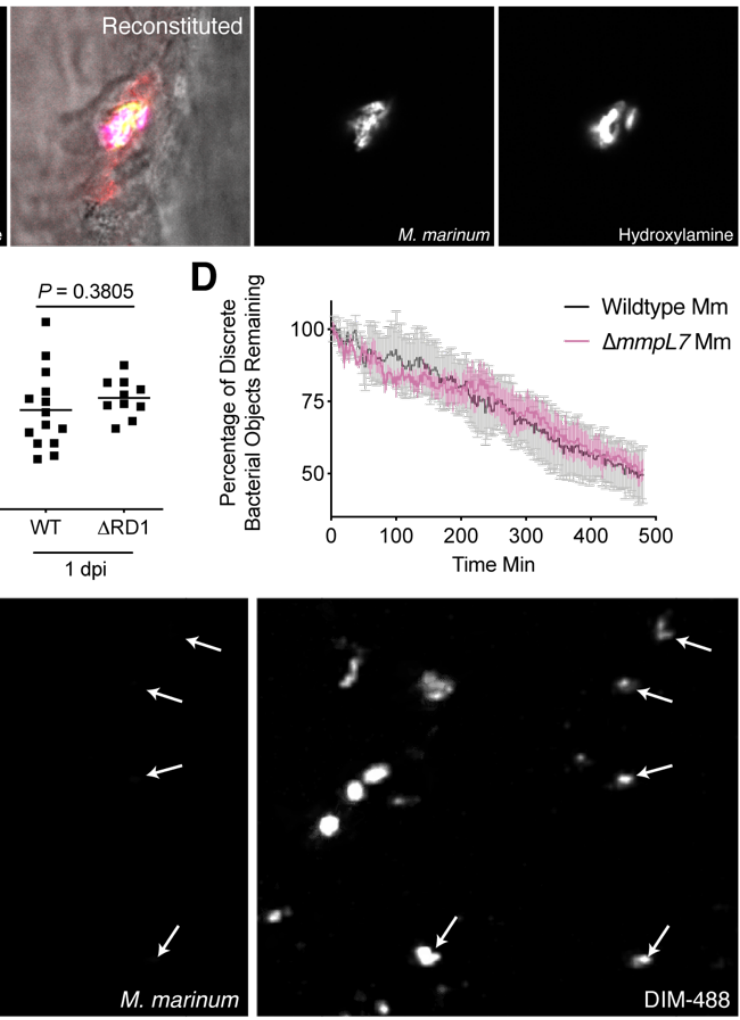

DIM-488

$\mathbf{F}$
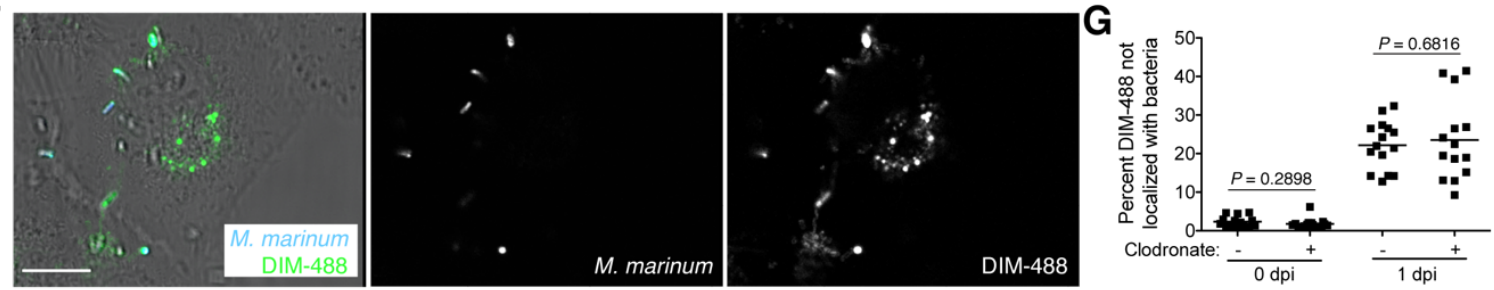

Supplemental Figure 3. Functional evaluation of PDIM spread. (A) Images of control or reconstituted $M$. marinum expressing a cytosolic green fluorescent protein labeled with periodate-hydroxylamine chemistry at $3 \mathrm{hpi}$ of $\sim 100 \mathrm{M}$. marinum into the HBV of transgenic fish whose macrophages express a fluorescent protein, scale bar $=10 \mu \mathrm{m}$. (B) Mean percent fluorescent signal not localized with bacteria following HBV infection of wildtype fish with 100 control or reconstituted $M$. marinum labeled with periodate-hydroxylamine chemistry. Two-tailed, unpaired t test. (C) Mean percent DIM-488 not localized with bacteria following HBV infection of wildtype fish with $\sim 100$ wildtype or $\Delta$ RD1 M. marinum. Two-tailed Mann Whitney test for 0 dpi and two-tailed, unpaired t test for $1 \mathrm{dpi}$ (D) Mean (+/- SEM) percentage of discrete bacterial objects remaining following HBV infection of wildtype fish with $\sim 100$ wildtype or $\triangle m m p L 7 M$. marinum. Representative of two separate experiments. (E) Image of $M$. marinum expressing a cytosolic blue fluorescent protein reconstituted with DIBO-488 labeled azido-DIM (DIM-488) highlighting DIM-488 spread on epithelial cells (arrows) at $24 \mathrm{hpi}$ of $\sim 100 \mathrm{M}$. marinum in the HBV of transgenic fish whose macrophages express a fluorescent protein, scale bar $=30 \mu \mathrm{m}$. $(\mathbf{F})$ Image of $M$. marinum expressing a blue fluorescent protein reconstituted with DIM-488 24 hpi of A549 epithelial cells at an MOI of 5, scale bar $=10 \mu \mathrm{m}$. (G) Mean percent DIM-488 not localized with bacteria following HBV infection of lipo-PBS or lipo-clodronate treated fish with $\sim 100 \mathrm{M}$. marinum. Two-tailed Mann Whitney test for $0 \mathrm{dpi}$ and two-tailed, unpaired test for $1 \mathrm{dpi}$ (B), (C), and (G) representative of three separate experiments. 
A

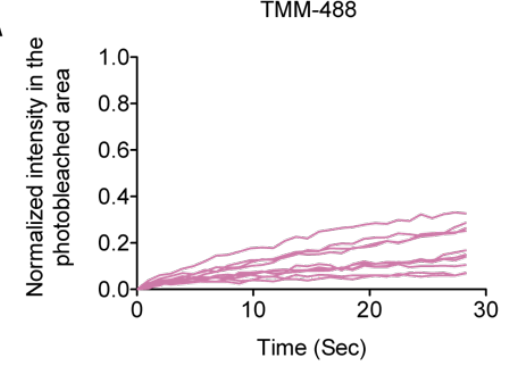

C

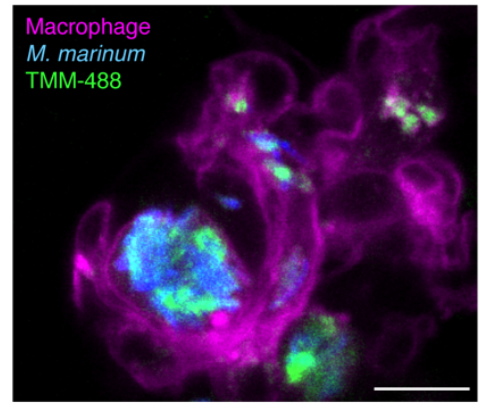

B

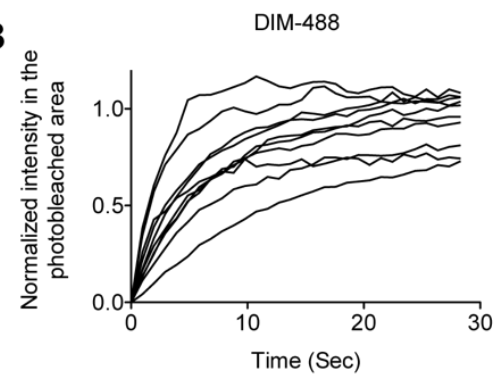

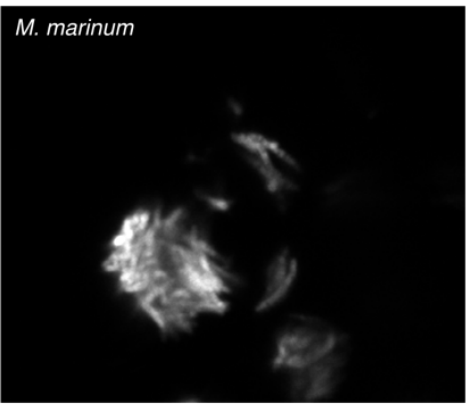

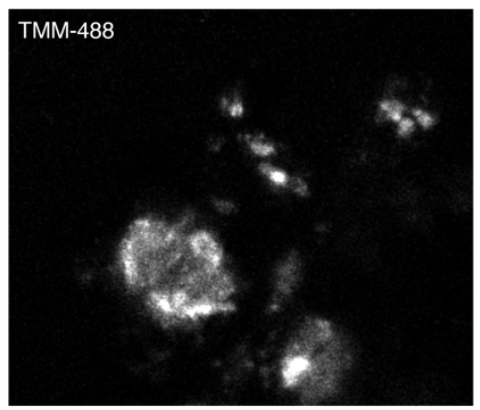

Supplemental Figure 4. Individual FRAP curves of (A) TMM-488 and (B) DIM-488 labeled bacteria. (C) Image of $M$. marinum expressing a cytosolic blue fluorescent protein metabolically labeled with 6-azido trehalose followed by labeling with DIBO-488 (TMM-488) highlighting TMM-488 spread across macrophage membranes at $24 \mathrm{hpi}$ of $100 \mathrm{M}$. marinum in the HBV of transgenic fish whose macrophages express a 


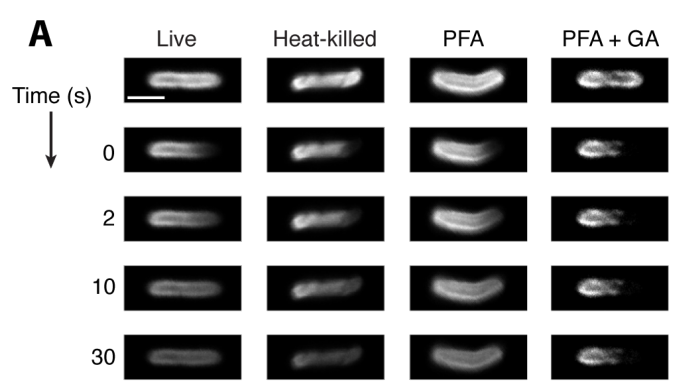

D

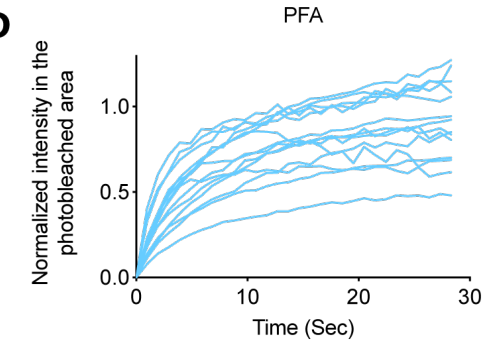

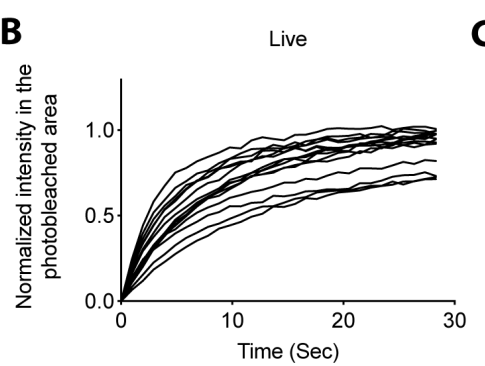

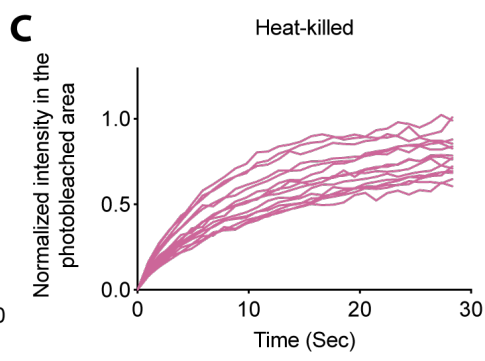

$P F A+G A$

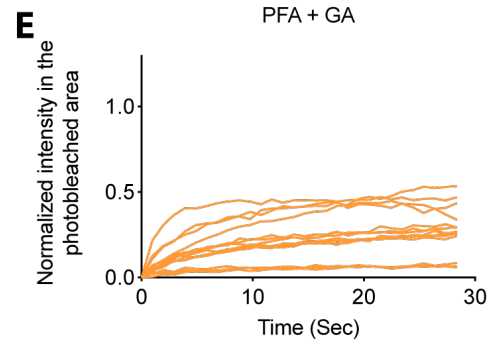

Supplemental Figure 5. FRAP analysis of DIM-488 labeled bacteria. (A) Representative FRAP images of live, heat-killed, PFA, and PFA+GA treated DIM-488 labeled M. marinum, scale bar $=2 \mu \mathrm{m}$. (B-E) Individual 


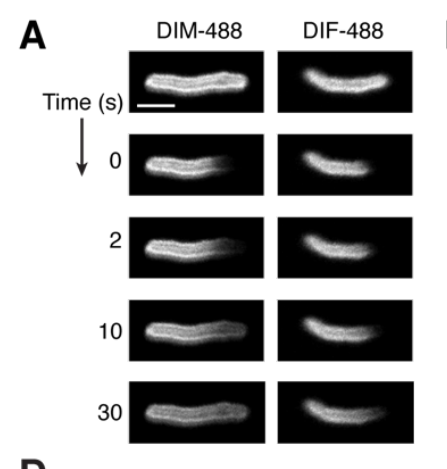

B

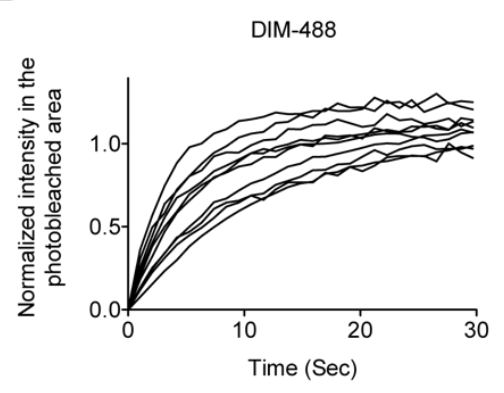

D

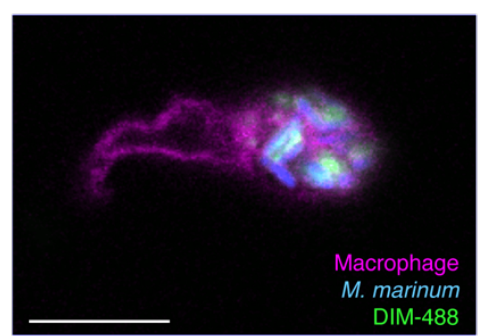

E
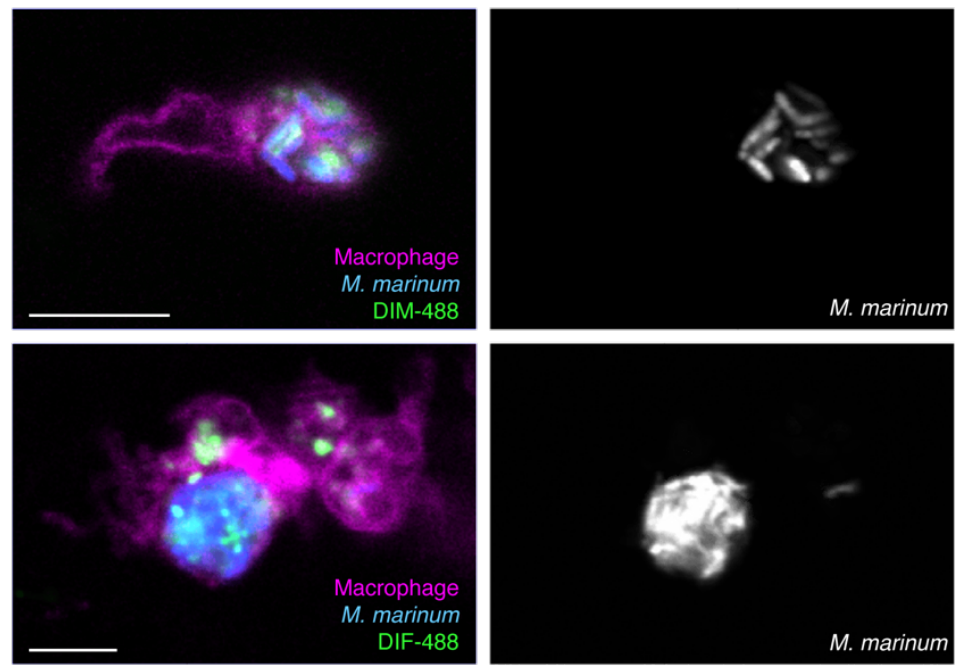

C
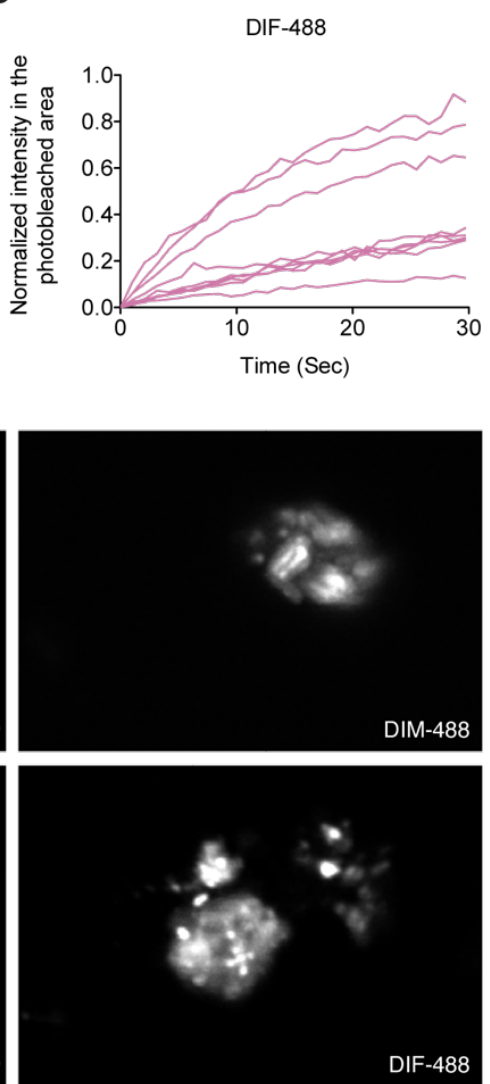

Supplementary Figure 6. Analysis of DIM-488 and DIF-488 labeled M. marinum. (A) Representative FRAP images of DIM-488 and DIF-488 labeled $M$. marinum, scale bar $=2 \mu \mathrm{m}$. Individual fluorescent recovery curves of (B) DIM-488 and (C) DIF-488 labeled M. marinum. Images of $M$. marinum expressing a cytosolic blue fluorescent protein reconstituted with green (D) DIM-488 or (E) DIF-488 at 24hpi of $\sim 100 \mathrm{M}$. marinum in the HBV of transgenic fish whose macrophages express a red fluorescent protein. Scale bar $=10 \mu \mathrm{m}$. (B) and $(\mathbf{C})$ represenatative of three separate experiments. 
A

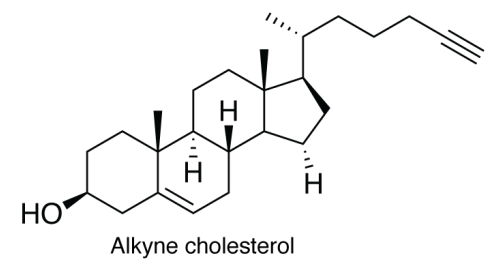

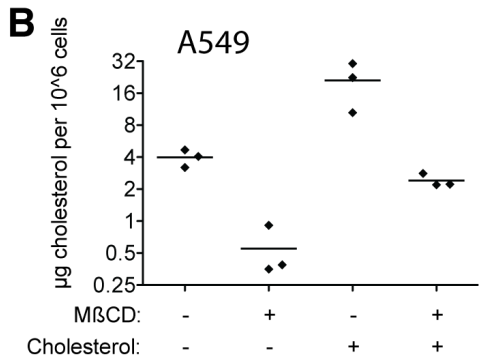

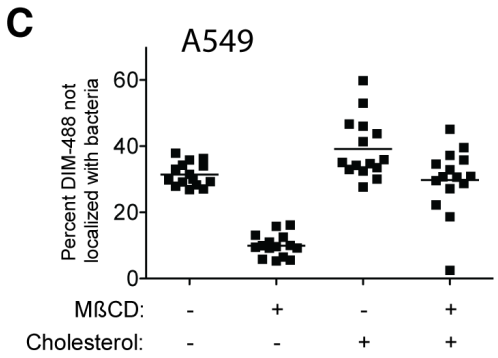

Supplementary Figure 7. Cholesterol mediates DIM-488 spread on A549 epithelial cells. (A) Structure of alkyne cholesterol. (B) Mean cholesterol content of A549 cells treated with methyl-B cyclodextrin (MBCD), water-soluble cholesterol, or both. (C) Mean percent DIM-488 spread at $24 \mathrm{hpi}$ of A549 epithelial cells treated with $\mathrm{MBCD}$, water-soluble cholesterol, or both, $\mathrm{MOI}=5$. (B) and (C) representative of three separate experiments. 
1187 Movie S1: PDIM dynamics. Real-time video of M. marinum expressing blue fluorescent protein

1188 reconstituted with DIBO-488 labelled azido-DIM at 3 hpi of the HBV with $\sim 100$ M. marinum.

1189

1190 Supplementary Table 1. Summary of $P$ values and statistical tests. Gaussian distribution was

1191 determined using the D'Agostino-Pearson normality test. The result of this test guided

1192 subsequent analyses.

1193

1194

1195

1196

1197

1198

1199

1200

1201

1202

1203

1204

1205

1206

1207

1208

1209

1210

1211

1212

1213

1214

1215

1216

1217 


\section{NMR SPECTRA}

1219

$1220 \quad{ }^{1} \mathrm{H}$ NMR

$1221500 \mathrm{MHz}$

$1222 \mathrm{CDCl}_{3}$

1223 PDIM

1224

1225

1226

1227

1228

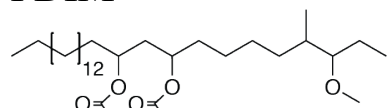

1229

1230

1231

1232

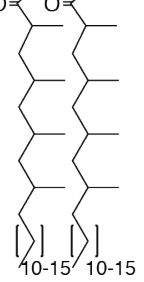

1233

$1234{ }^{13} \mathrm{C}$ NMR

$1235126 \mathrm{MHz}$

$1236 \mathrm{CDCl}_{3}$

1237

1238

1239

1240

1241

1242

1243

1244

1245

1246

1247

1248

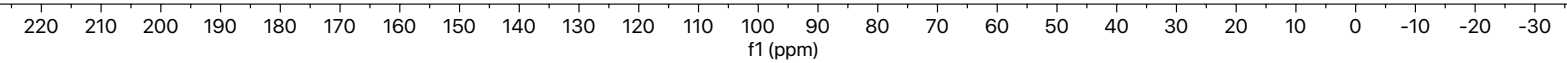


$1249{ }^{1} \mathrm{H}$ NMR

$1250 \quad 500 \mathrm{MHz}$

$1251 \mathrm{CDCl}_{3}$

1252 Azido-DIM

1253

1254

1255

1256

1257

1258

1259

1260

1261

1262

1263

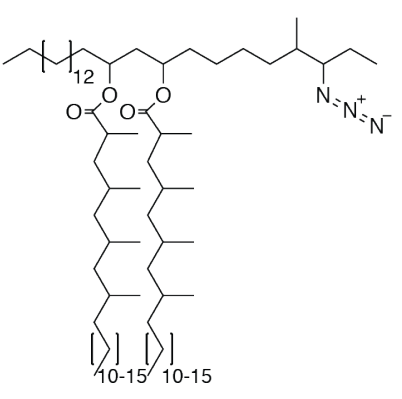

1264

$1265{ }^{13} \mathrm{C}$ NMR

$1266126 \mathrm{MHz}$

$1267 \mathrm{CDCl}_{3}$

1268

1269

1270

1271

1272

1273

1274

1275

1276

1277

1278

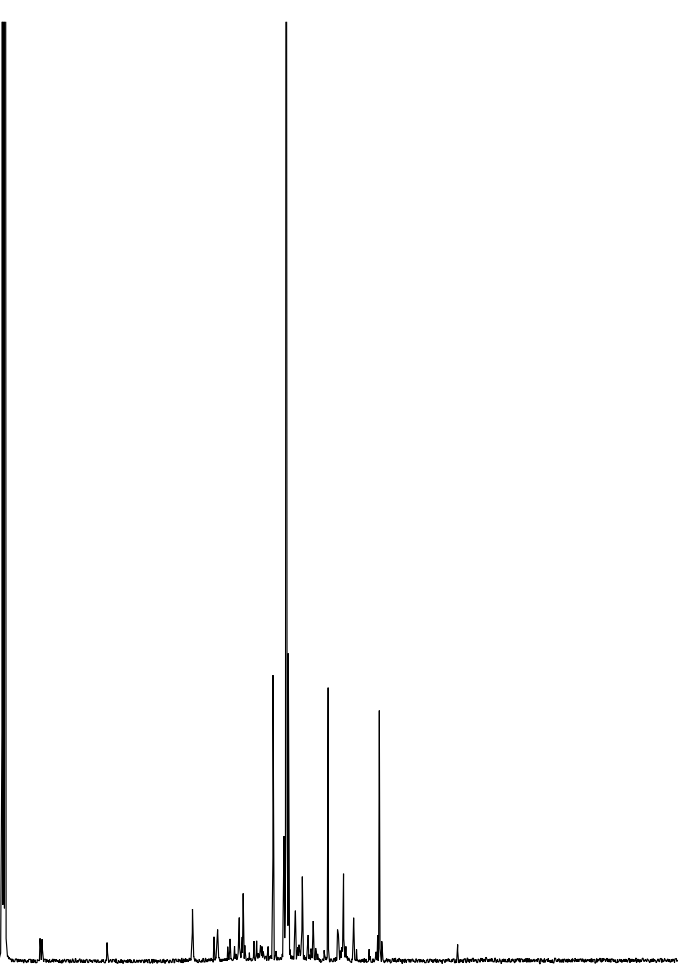

1279

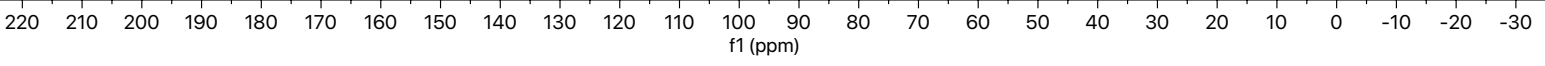


$1280{ }^{1} \mathrm{H}$ NMR

$1281500 \mathrm{MHz}$

$1282 \mathrm{CDCl}_{3}$

1283 PDIF

1284

1285

1286

1287

1288

1289

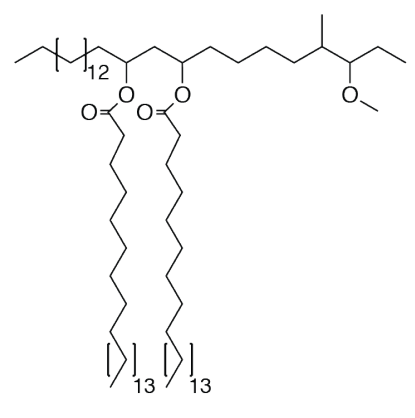

1290

1291

1292

1293

1294

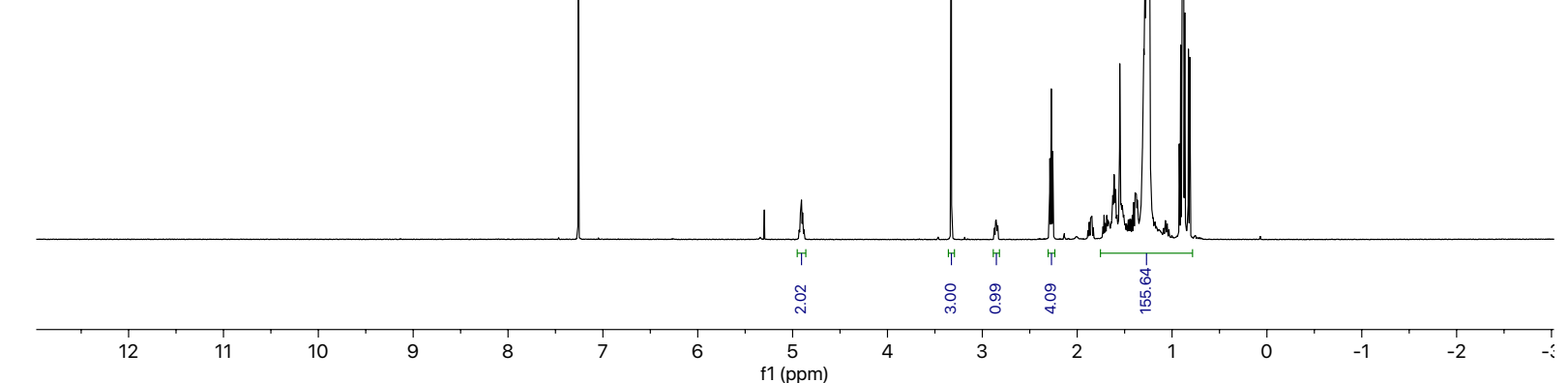

1295

$1296{ }^{13} \mathrm{C}$ NMR

$1297 \quad 126 \mathrm{MHz}$

$1298 \mathrm{CDCl}_{3}$

1299

1300

1301

1302

1303

1304

1305

1306

1307

1308

1309

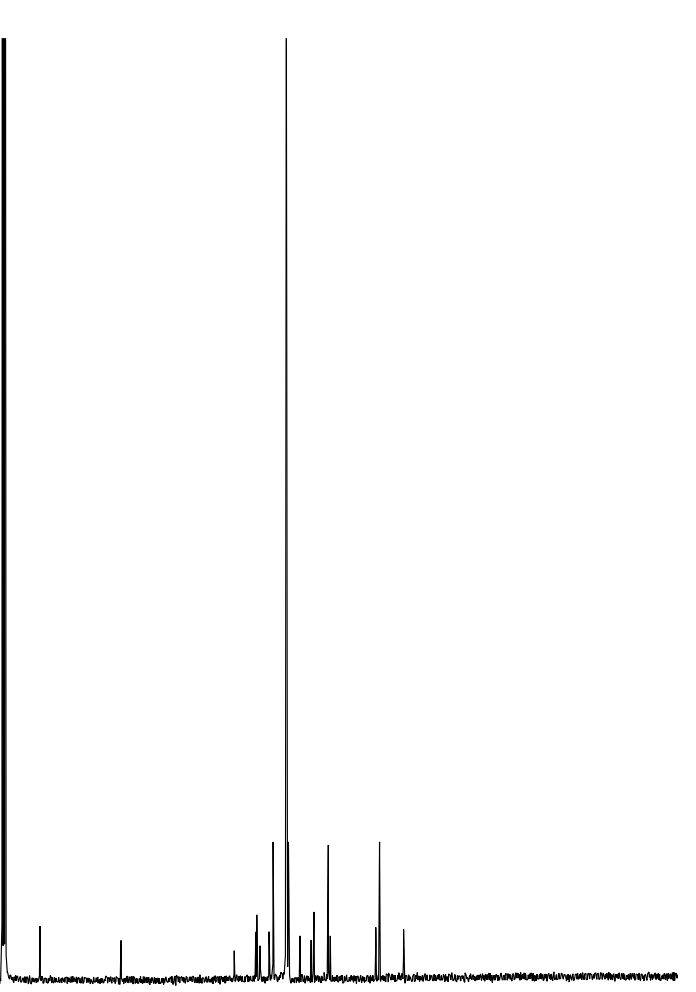

1310 


\section{$1311 \quad{ }^{1} \mathrm{H}$ NMR}

$1312500 \mathrm{MHz}$

$1313 \mathrm{CDCl}_{3}$

\section{Azido-DIF}

1315

1316

1317

1318

1319

1320

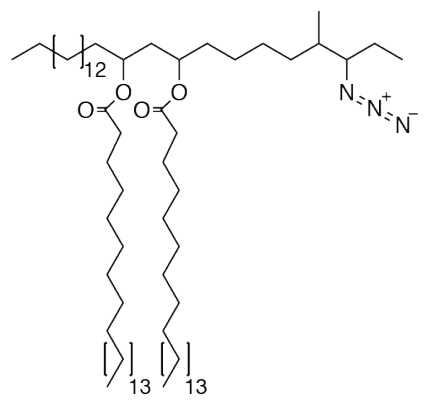

1321

1322

1323

1324

1325

1326

1327

$1328{ }^{13} \mathrm{C}$ NMR

$1329126 \mathrm{MHz}$

$1330 \quad \mathrm{CDCl}_{3}$

1331

1332

1333

1334

1335

1336

1337

1338

1339

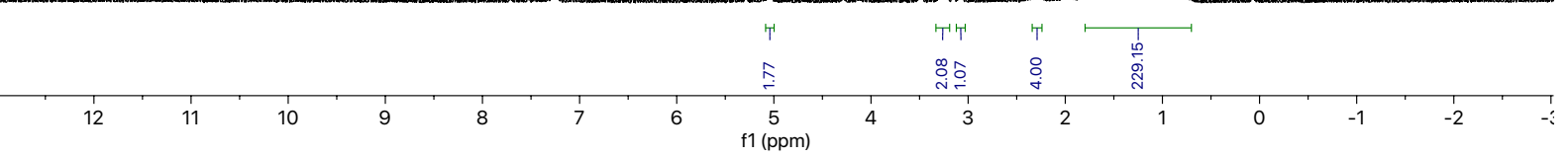

